$$
\begin{aligned}
& \text { CONF-951057-11 } \\
& \text { ANL/CMT/CP--86178 }
\end{aligned}
$$

\title{
TRUEX Processing of Plutonium Analytical Solutions at Argonne National Laboratory
}

\author{
David B. Chamberlain, Cliff Conner, Joseph C. Hutter, Ralph A. Leonard, \\ David G. Wygmans, and G. F. Vandegrift \\ Chemical Technology Division \\ Argonne National Laboratory \\ 9700 South Cass Avenue \\ Argonne, IL 60439
}

\begin{abstract}
The submitted manuscript has been authored by a contractor of the U.S. Government under contract No. W-31-109-ENG-38. Accordingly, the U.S. Government retains a nonexclusive, royalty-free license to publish or reproduce the published form of this contribution, or allow others to do so, for U.S. Government purposes.
\end{abstract}

Camera-ready paper submitted for publication in the journal Separation Science and Technology as part of the issue devoted to the proceedings of the "Ninth Symposium on Separation Science and Technology for Energy Applications," Gatlinburg, Tennessee, October 22-26, 1995 


\section{DISCLAMMER}

Portions of this document may be illegible in electronic image products. Images are produced from the best available original document. 


\title{
TRUEX PROCESSING OF PLUTONIUM ANALYTICAL SOLUTIONS AT ARGONNE NATIONAL LABORATORY
}

\author{
David B. Chamberlain, Cliff Conner, Joseph C. Hutter, \\ Ralph A. Leonard, David G. Wygmans, and George F. Vandegrift \\ Argonne National Laboratory \\ 9700 South Cass Avenue \\ Argonne, IL 60439 \\ Phone: $708 / 252-7699$ \\ FAX: $708 / 252-5246$
}

\begin{abstract}
The TRUEX (TRansUranic EXtraction) solvent extraction process was developed at Argonne National Laboratory (ANL) for the Department of Energy. A TRUEX demonstration completed at ANL involved the processing of analytical and experimental waste generated there and at the New Brunswick Laboratory. A 20 -stage centrifugal contactor was used to recover plutonium, americium, and uranium from the waste. Approximately $84 \mathrm{~g}$ of plutonium, $18 \mathrm{~g}$ of uranium, and $0.2 \mathrm{~g}$ of americium were recovered from about $118 \mathrm{~L}$ of solution during four process runs. Alpha decontamination factors as high as 65,000 were attained, which was especially important because it allowed the disposal of the process raffinate as a lowlevel waste. The recovered plutonium and uranium were converted to oxide; the recovered americium solution was concentrated by evaporation to approximately $100 \mathrm{~mL}$.

The flowsheet and operational procedures were modified to overcome process difficulties. These difficulties included the presence of complexants in the feed, solvent degradation, plutonium precipitation, and inadequate decontamination factors during startup. This paper will discuss details of the experimental effort.
\end{abstract}

This submitted manuscript has been authored by a contractor of the U. S. Government under contract No. W-31-109-ENG-38. Accordingly, the U. S. Government retains a non-exclusive, royalty-free license to publish or reproduce the published torm of this contribution, or allow others to do so, for U. S. Government purposes. 


\section{INTRODLCTION}

A three-year program was funded by the Office of Waste Operations and the Office of Technology Development, Environmental Restoration and Environment and Waste Management, to process approximately 118 liters of waste solution generated during the analysis of plutonium samples at the New Brunswick Laboratory (NBL) and Argonne National Laboratory (ANL). These residues, stored in over three hundred sample bottles, contained varying concentrations of nitric, sulfuric, phosphoric, and hydrochloric acids, as well as uranium, plutonium, neptunium, and americium. The TRUEX (TRansUranic EXtraction) process was used to convert the bulk of this waste into a nonTRU low-level waste. The goal was to reduce the TRU elements to a concentration less than $10 \mathrm{nCi} / \mathrm{mL}$ so that the waste could be disposed of as non-transuranic waste.*

The objectives of this program were fivefold. First, we wanted to demonstrate the applicability of the TRUEX process to handle a variety of real waste solutions. This program also was designed to give us experience in using the Generic TRUEX Model for designing flowsheets for specific feeds and process goals.

Second, we wanted to treat these waste solutions in order to solve a wastetreatment/storage problem here at ANL. These waste solutions were being stored in small polyethylene bottles (typically $250-\mathrm{mL}$ ). These bottles were wrapped in plastic, sealed inside a plastic pouch, and stored inside 5-gallon carbon-steel pails. As these wastes contained both high acid concentrations and high alpha-activity levels, the bottles were beginning to degrade and become brittle. Either recovering the TRU as useful products or converting them to a stable, solid waste form would alleviate ANL's waste storage problem.

Third, we wanted to produce a raffinate that was suitable for conventional lowlevel waste disposal. The initial goal of this process was to generate a nonTRU raffinate that was less than $10 \mathrm{nCi} / \mathrm{mL}$. During the processing of batch 1 , our Environment and Waste Management (EWM) organization required us to lower the TRU limit by a factor of 100 , to $0.1 \mathrm{nCi} / \mathrm{mL}$. At this level, the waste could be concentrated in the existing ANL low-level waste evaporators without any other treatment. Equipment and process limitations, however, prevented us from reaching

\footnotetext{
* The TRU limit for waste is $100 \mathrm{nCi} / \mathrm{g}$; our $10 \mathrm{nCi} / \mathrm{mL}$ limit is well below this limit.
} 
this god. The raffinate generated by ar processing runged from a $\mathrm{nCi} / \mathrm{mL}$ to approximately $10 \mathrm{nCi} / \mathrm{mL}$

Fourth. we wanted to recover plutonium. uranium. and americium from these waste solutions and return them to the DOE complex. It was initially planned to convert the recovered plutonium to a metal. Shortly after the start of the program. however, the political climate changed. eliminating the demand for plutonium. Therefore, most of the recovered plutonium and uranium was returned to EWM for disposal. The americium recovered was retained for use in on-going experiments at ANL.

Fifth, we wanted to pave the way for others contemplating the installation of a TRUEX facility. This demonstration showed the applicability of using the TRUEX process for treating similar wastes at Rocky Flats, Los Alamos, Hanford, and Idaho.

In this paper, we will discuss a variety of process- and operational-related challenges that were encountered in this program. These challenges included (1) space limitations, (2) batch operation, (3) variable batch composition, (4) high plutonium concentration, (5) need to limit product volumes, (6) foam generation, (7) solvent cleanup, (8) poor process results during startup, and (9) suspended solids. Methods employed to overcome these challenges are described, as are some of the processing results. For more detailed information on this program, see $[1,2,3,4,5,6$, $7,8,9,10]$.

\section{APPROACH}

TRUEX is a solvent-extraction process developed at ANL to remove and recover transuranic material from acid waste solutions. It uses a solution of $1.4 \mathrm{M}$ tributyl phosphate (TBP) and 0.2M n-octyl(phenyl)-N,Ndiisobutylcarbamoylmethylphosphine oxide (CMPO) diluted by $n$-dodecane (nDD). This solvent is commonly called by the abbreviated name TRUEX-nDD. A simplified schematic of a TRUEX process is shown in Fig. 1. All of the typical sections of a TRUEX process were required to process these wastes, including extraction, scrub, americium and plutonium strips, and solvent cleanup. Details of the TRUEX process are described elsewhere $[11,12,13]$.

The TRUEX process is ideally suited for processing these wastes solutions; nonTRU raffinates were generated, while the americium and plutonium were recovered separately for reuse. The TRUEX process was run in a 20 -stage 4 -cm centrifugal contactor installed in a plutonium glovebox. Because of space limitations in the glovebox and criticality-control requirements, the amount of material that 


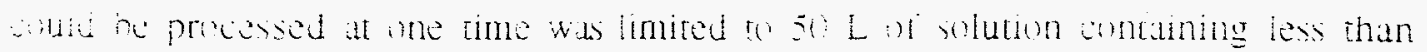
50 grams at tissile material (Pu plus 235 C. Because the amount of waste to be processed axceeded both these limits. it was split up into six difterent batches. Wastes were batched together based upon (1) similar characteristics, such as acid and actinide content, (2) presence of complexants, (3) the need to keep batch size as close to $50 \mathrm{~L}$ as possible, and (4) the need to limit the $\mathrm{HCl}$ concentration so that acceptable corrosion rates in stainless steel equipment were maintained. Of the six batches available, four were processed in this program. The remaining waste will be treated using more traditional means without attempting to recover any of the TRU components [14]. In addition to these four batches, three additional runs were completed to process secondary wastes generated during processing and cleanout of the system.

The process steps required to process these waste solutions are shown in Fig. 2. A brief description of these steps follows. Based upon the waste forms, the waste was segregated into batches; then one batch contained in several 5-gallon storage pails was moved from EWM to our laboratory for transfer into the glovebox. Each 5-gallon pail, containing up to 26 waste bottles, was unpacked by removing each bottle of waste and bagging it into the glovebox. Once inside the glovebox, the waste was transferred into the 50-L feed (batch) tank. The empty bottles were rinsed with nitric acid, then bagged out of the glovebox. After mixing, sampling, and bagout of the sample vial, a sample aliquot was counted using high-resolution gamma spectroscopy to determine the americium content. An aliquot was also counted by liquid scintillation to estimate the plutonium content. Batch extractions were then completed The Generic TRUEX Model (GTM) $[15,13,16]$ was used to design the extraction, scrub, and americium strip sections. The plutonium strip could not be modeled because neither sodium oxalate nor ammonium oxalate were included in the GTM. Once the flowsheet was designed to meet process goals, a sensitivity analysis was completed to determine which variables in the flowsheet were most likely to affect the process.* For the initial waste solutions processed, a series of batch extractions, scrubs, and strips were completed to estimate the expected distribution coefficients ( $D$ values) in the various sections of the flowsheet and to verify the GTM predictions.** . Based upon the GTM sensitivity analysis and the batch-extraction data, a flowsheet was developed to satisfy the operational requirements for that particular batch. The equipment in the laboratory was then set up, pumps calibrated, and feed solutions prepared.

* For more information on how a sensitivity analysis is completed, see [17].

${ }^{* *}$ A distribution coefficient, or D value, is defined as the concentration of an element in the organic phase divided by its concentration in the aqueous phase. 
The ime needed to actually process the ante depended upon the feed flow rate and the amount of solution requiring processing. Processing $50 \mathrm{~L}$ of waste at a flow rate of $100 \mathrm{~mL} / \mathrm{min}$ took 500 minutes $(8.3$ hours?. Startup. shutdown. and system cleanout at the end of the run often added $3-4$ more hours to the test. Thus, each batch was typically processed over the course of 2-3 days.

Five solutions were generated during operation: nonTRU raffinate, americium strip. plutonium strip, carbonate wash, and the acid rinse waste. The nonTRU raffinate was further treated to make it acceptable for handling by EWM. The solution was neutralized with $\mathrm{NaOH}$ so that the final $\mathrm{pH}$ was between 6 and 9. The americium product stream, which contained $\mathrm{Am}\left(\mathrm{NO}_{3}\right)_{3}$ plus $\mathrm{HNO}_{3}$, was concentrated by evaporation and stored in a lead-lined safe for future use. The plutonium product stream, which also contained the uranium, was processed by evaporating it to dryness, then calcining the solids in an oven at $\geq 600^{\circ} \mathrm{C}$ to produce $\mathrm{PuO}_{2}$. Most of the oxide was returned to EWM for storage and subsequent disposal; some of the material was stored for ongoing experiments. The sodium carbonate solutions were acidified by adding nitric acid, then recycled to the TRUEX process by mixing them with the feed for the next batch. The acid rinse solution was combined with the acidified carbonate. Recycling these solutions was completed to recover the TRU content of this waste.

A fifth waste solution was generated during the cleanup of the centrifugal contactors after each run. This flush solution was typically acidic (nitric acid), though carbonate solutions were also used. They were added with the acidified carbonate solutions to the next batch.

\section{PROCESS AND OPERATIONAL CHALLENGES}

\section{Space Limitations}

Because of limited space in the existing glovebox, we had to limit the number of stages in the flowsheet to 20 . Installation of 20 centrifugal contactor stages and a 50-L feed tank left very limited additional room for other equipment and tanks. To collect the extraction section raffinate, a 110 -L container was needed. Because a tank this large would not fit into the glovebox, a line was installed connecting the glovebox to an adjacent hood. As the raffinate was generated, it was pumped into $20-\mathrm{L}$ carboys in this hood. This arrangement facilitated sampling of the raffinate, since the need to bag samples out of the glovebox was eliminated. We also placed all of the nonradioactive feed tanks and pumps outside of the glovebox to ease handling and help 
ale rom in the glowehox. This arrangmen will te thown later an a figure describing the hatch ? flowsheet.

Batch Operation

Splitting the waste into batches created a number of unique obstacles and challenges in this program. Batch operation required much more time to complete this program than a continuous process would have. Some of the factors that extended the program included (1) the need to develop and test four different flowsheets, one for each batch of waste, (2) the need to prepare for each run, including equipment setup, calibration, and solution preparation, and (3) the need to clean up after each run and process the resulting wash/product solutions. Blending of all of the waste solutions was considered, but the appropriate facilities to complete this type of operation were not available.

Batch operation also created a larger volume of waste. The centrifugal contactors were started up with a nonradioactive feed solution. Once the operation was stable, the radioactive feed was cut in. In spite of these actions, some of the initial extraction section raffinate had to be recycled. (This is discussed in more detail later.) Shutting down the system also generated waste. Once all of the feed was processed, the system was operated for another 10-20 minutes to help clean it out. After shutdown, the stages were drained; in some instances, decontamination flushes were completed to reduce the activity in the extraction and carbonate wash sections and solvent holding tank. All of these actions create additional waste.

Changing the extraction-section nonTRU raffinate criteria (by EWM) from $<100 \mathrm{nCi} / \mathrm{mL}$ to $<0.1 \mathrm{nCi} / \mathrm{mL}$ created a great deal of additional waste. All of the raffinate from batch 1 was reprocessed using a modified TRUEX process. Because of equipment contamination, operational problems, flowsheet limitations, and attempts to limit the volume of waste generated, the lower limit could not be achieved. After several unsuccessful attempts to reach $0.1 \mathrm{nCi} / \mathrm{mL}$, the lower limit was abandoned.

Splitting the waste into batches had some positive consequences. Because we had to develop four different flowsheets, we gained some experience in using the GTM, and we learned which parts of the GTM were more accurate than others. Operating the centrifugal contactors with four different flowsheets enabled us to demonstrate the flexibility of both the equipment and the TRUEX process. Lessons learned from one batch was also used to improve the flowsheet for subsequent batches. 


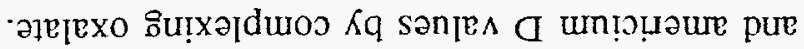

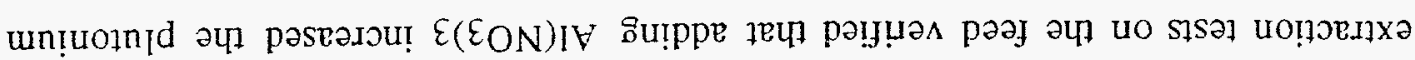

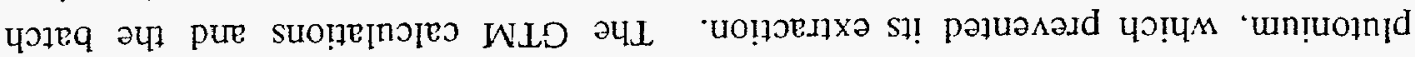

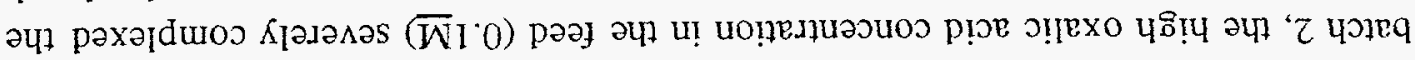

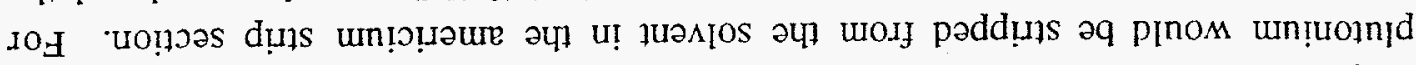

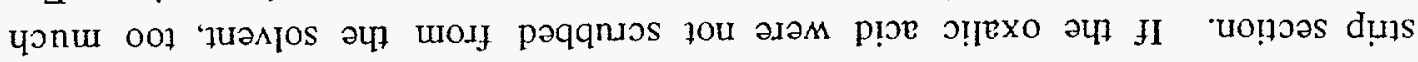

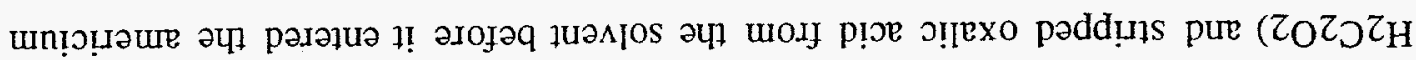

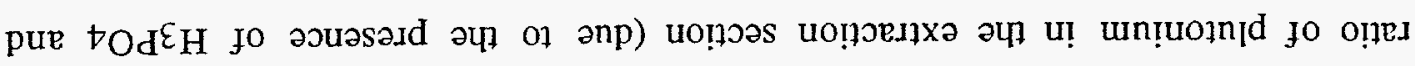

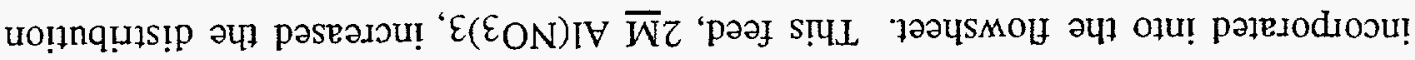

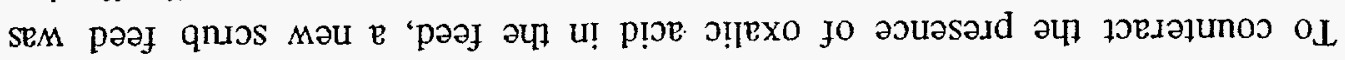

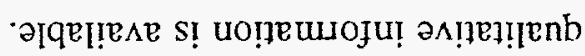

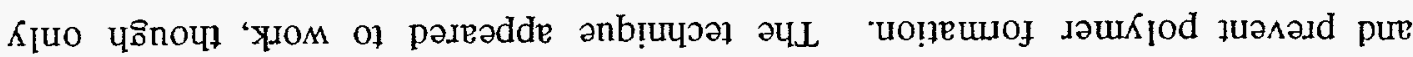
un!̣uołn

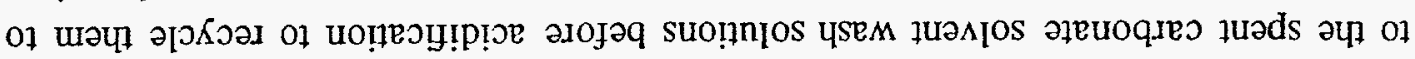

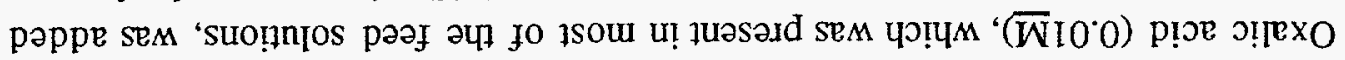

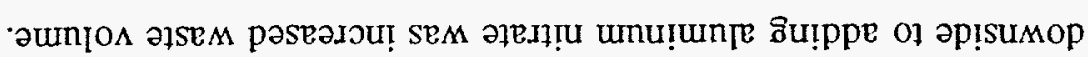

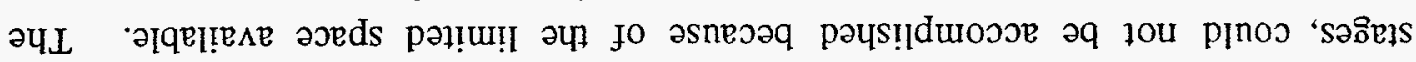

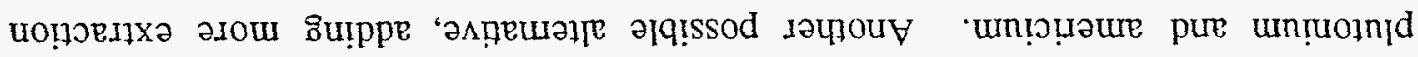

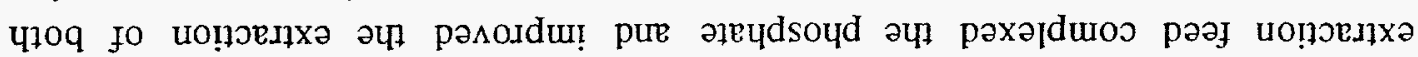

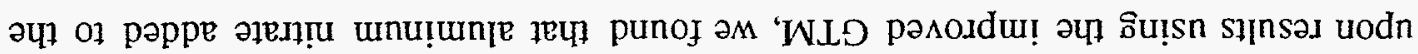

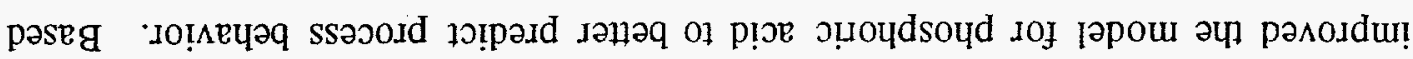

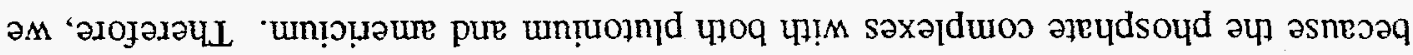

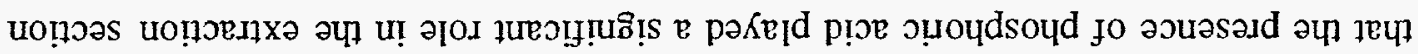

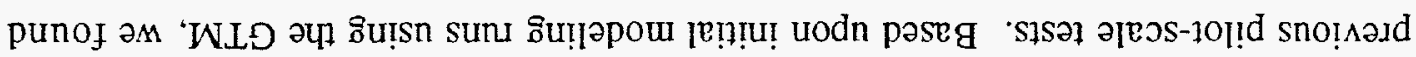

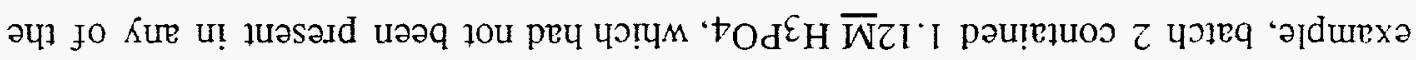

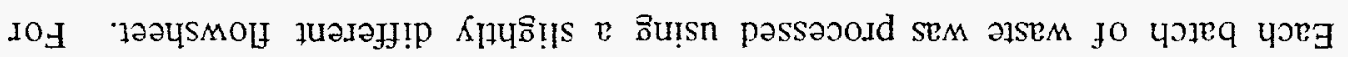

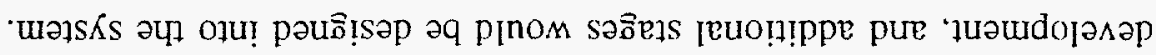

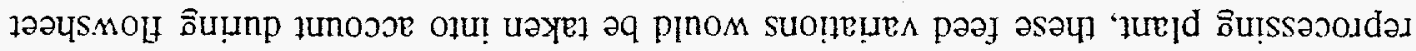

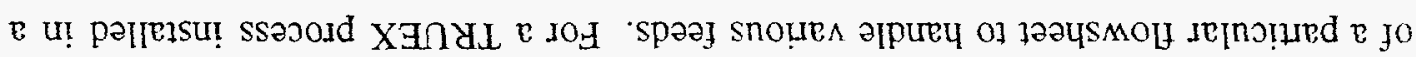

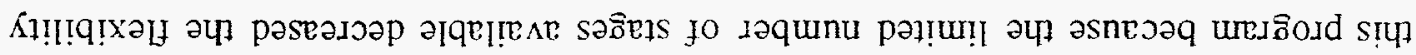

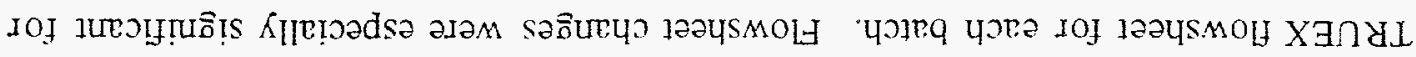

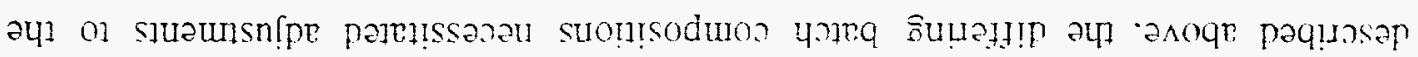

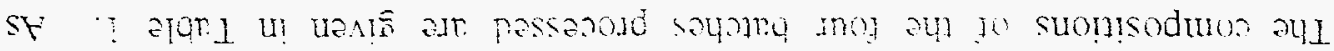


TABLE I. COMPOSITION OF BATCHED WASTE PROCESSED LSING THE TRLEX PROCESS

\begin{tabular}{|c|c|c|c|c|c|}
\hline & \multicolumn{4}{|c|}{ Batch } & \multirow[b]{2}{*}{ Total } \\
\hline & $T$ & 2 & $\overline{3}$ & 4 & \\
\hline Volume of original waste, $\mathrm{La}^{\mathrm{a}}$ & $1 \mathrm{~b}$ & 34.3 & 41.8 & 41.0 & 118.1 \\
\hline No. bottles of original wastec & 1 & 55 & 135 & 145 & 336 \\
\hline \multicolumn{6}{|l|}{ Elemental analysis, $\mathrm{g}$} \\
\hline Total $\mathrm{Pu}$ & 12 & 13.28 & 33.93 & 28.50 & 87.71 \\
\hline $\mathrm{Pu}-239$ & 11.3 & 11.99 & 31.13 & 26.14 & 80.56 \\
\hline $\mathrm{Pu}-240$ & 0.7 & 1.19 & 2.50 & 2.28 & 6.67 \\
\hline $\mathrm{Pu}-241$ & 0 & 0.10 & 0.30 & 0.07 & 0.47 \\
\hline Am-241 & $--d--$ & $--d--$ & $--d--$ & $1.17 \mathrm{E}-06$ & \\
\hline Total U & 0 & 16.27 & $25.73^{\mathrm{e}}$ & $28.79 \mathrm{f}$ & 70.79 \\
\hline$U-233$ & 0 & 0.00 & 0.48 & 0.00 & 0.48 \\
\hline$U-235$ & 0 & 10.03 & 0.19 & 0.80 & 11.02 \\
\hline U-238 & 0 & 6.24 & 25.06 & 27.99 & 59.29 \\
\hline $\mathrm{Np}-237$ & 0 & 0 & 1.57 & 0 & 1.57 \\
\hline
\end{tabular}

Acids, $\underline{M}$

\begin{tabular}{lrrrrr}
$\mathrm{HNO}_{3}$ & 4 & 2.39 & 1.69 & 4.51 & -- \\
$\mathrm{HCl}$ & 4 & 0.04 & 0.003 & 0 & -- \\
$\mathrm{H}_{2} \mathrm{SO}_{4}$ & 0 & 0 & 0.11 & 0 & -- \\
$\mathrm{H}_{3} \mathrm{PO}_{4}$ & 0 & 1.29 & 1.13 & 0.61 & -- \\
\hline
\end{tabular}

aThese volumes are of the original waste solutions and do not include recycled solutions such as acidified carbonate or cleaning solutions.

bThis waste was diluted to $24 \mathrm{~L}$ before processing to reduce corrosion rates to acceptable levels.

cThis row has the number of bottles received that contained waste.

d None reported.

${ }^{\text {e }}$ Based upon ICP analysis of the batched waste, only 7 grams of uranium actually present.

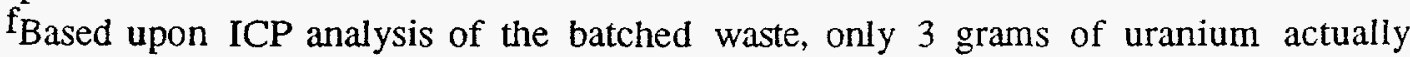
present.

Another challenge in this area was our reliance on waste forms to calculate solution compositions. Because a complete analysis was not completed on each batch (too expensive), we relied on the waste forms to predict what was present in solution. This reliance on waste forms can lead to significant errors and misinterpretation of the data. For example, the uranium concentration actually present in batches 3 and 4 was $27 \%$ and $10.4 \%$ of the reported amount (Table 1). The presence of unknown species, even at low concentrations, can also significantly affect the operation of the flowsheet. The use of batch extractions on the feed to validate GTM predictions helped to alleviate the potential problem of unexpected feed compositions. 


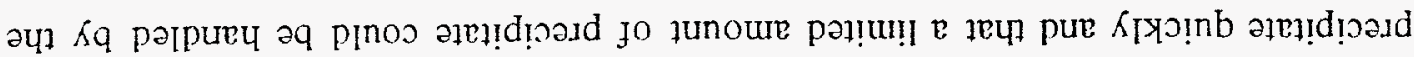

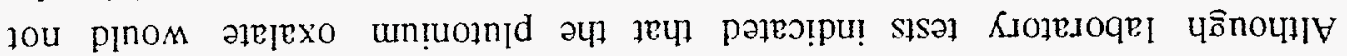

uoṇnjos dụ̂s

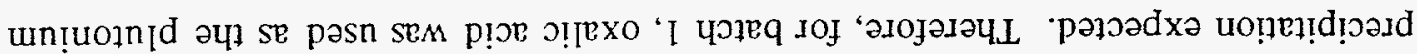

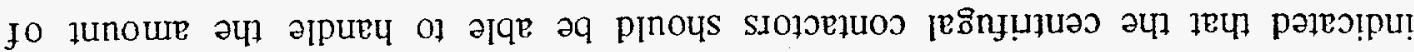

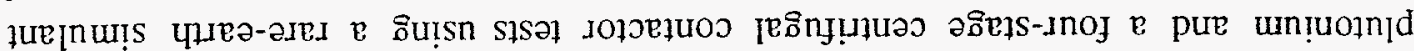

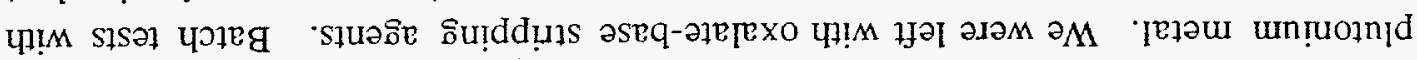
วonpoxd of pəau sassəวold әpழ̣on

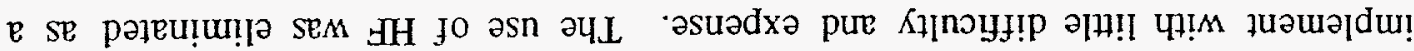

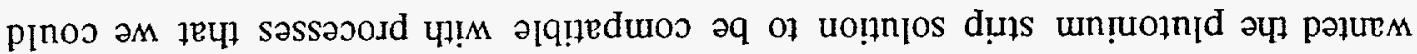

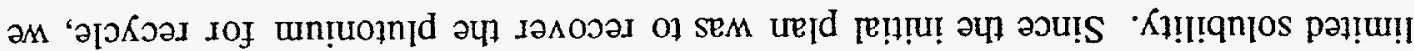

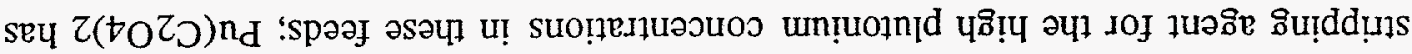

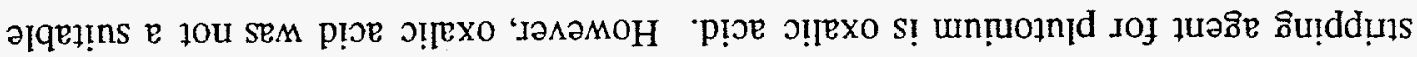

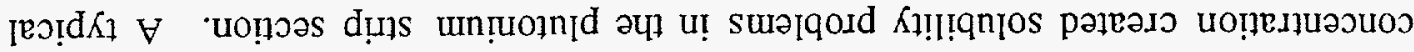

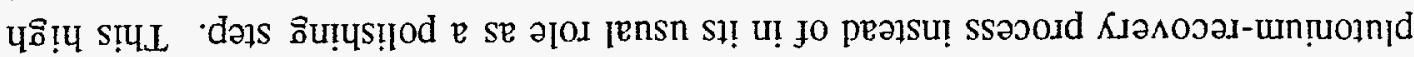

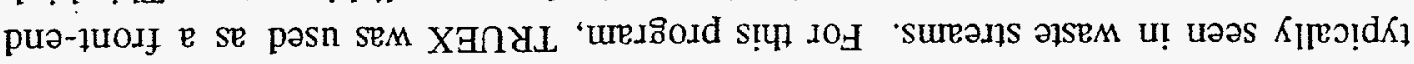

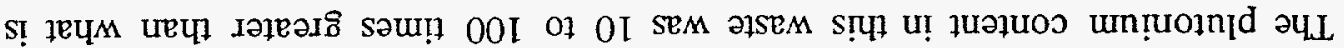

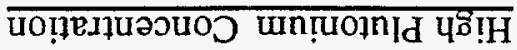

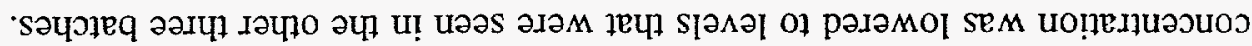

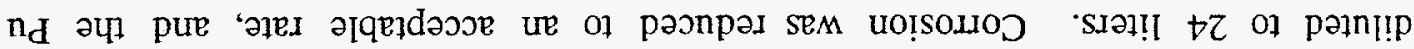

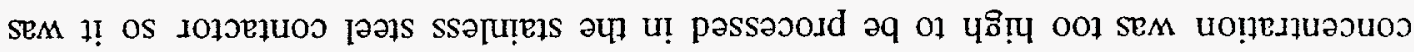

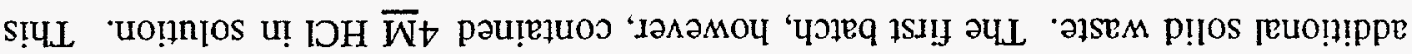

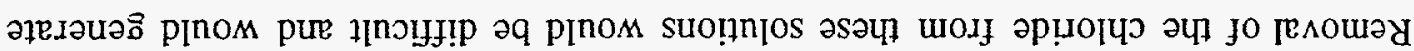

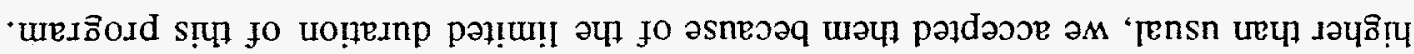

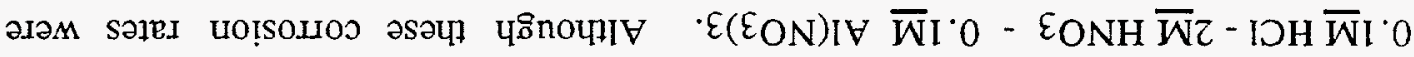

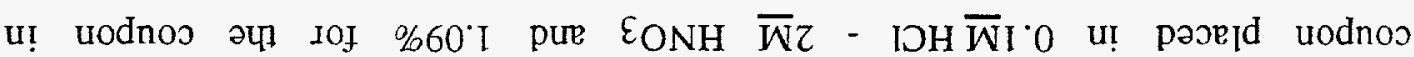

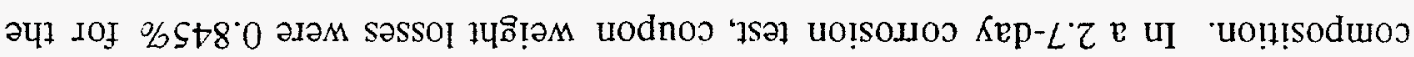

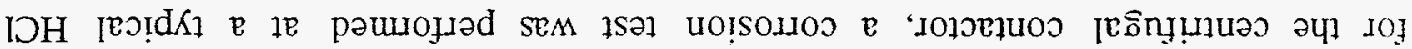
प

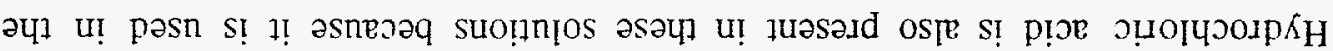

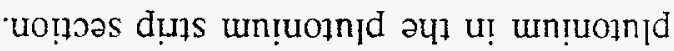

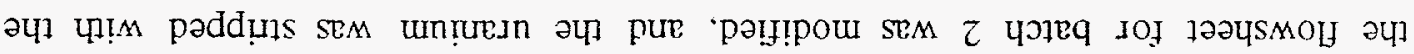

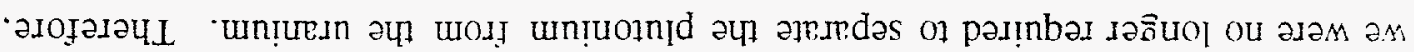

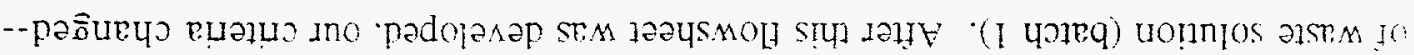

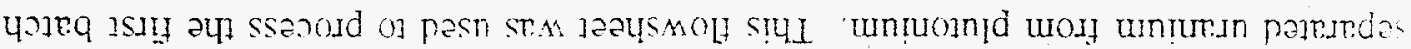

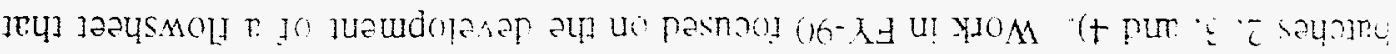

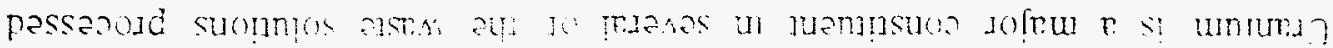




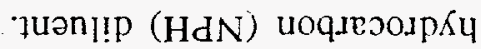

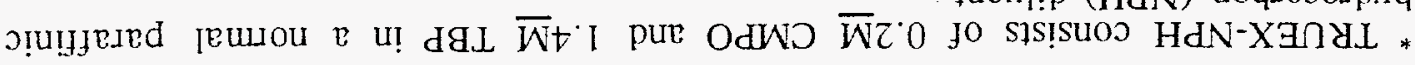

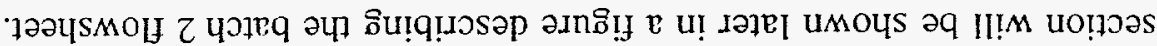

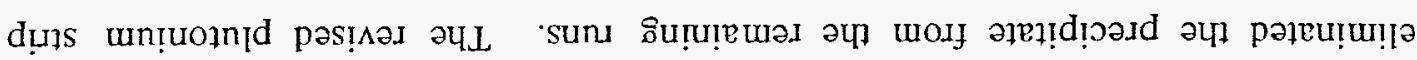

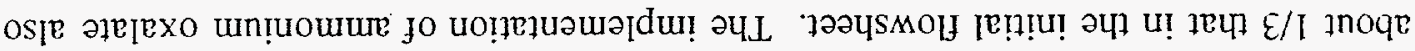

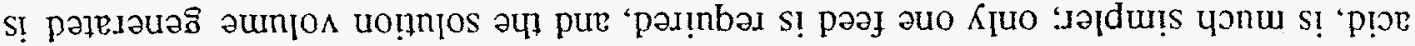

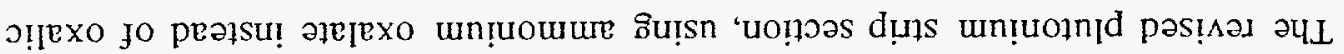

'un!̣oln

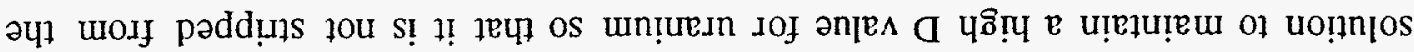

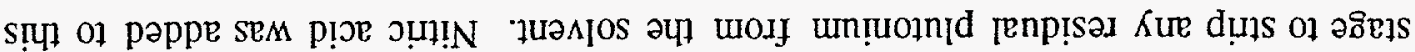

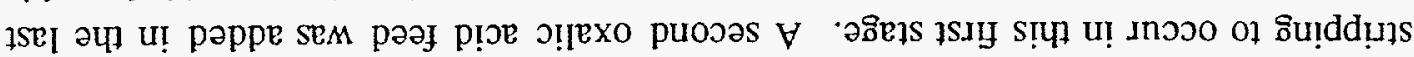

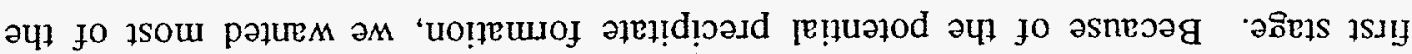

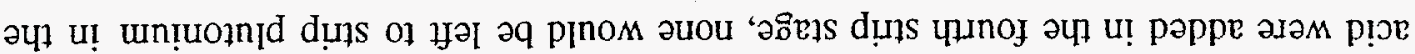

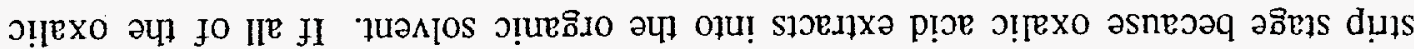

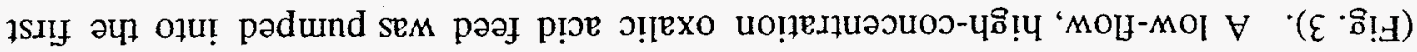

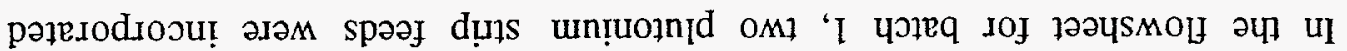

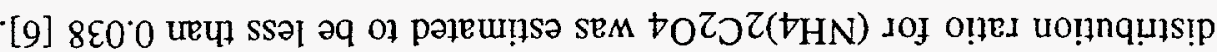

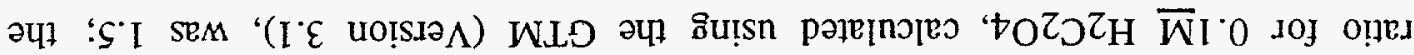

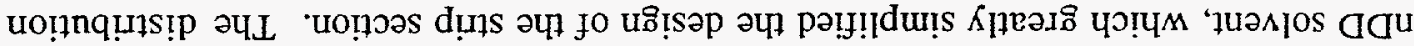

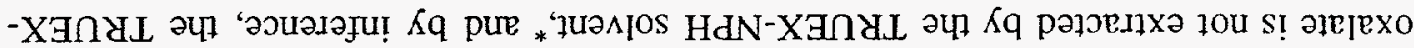

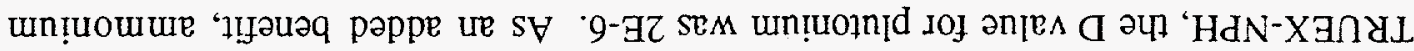

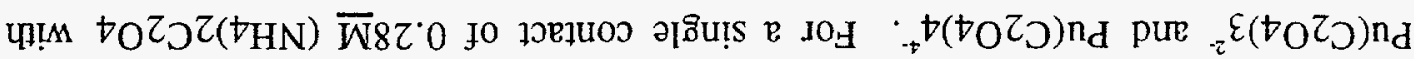

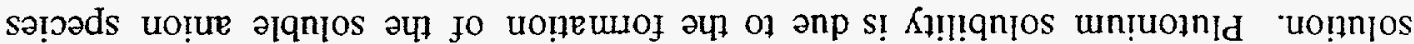

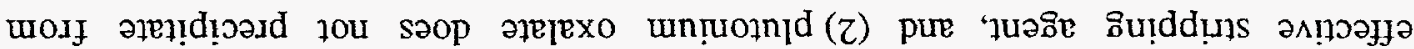
ue s! əle

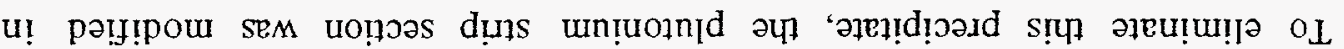

'ралวлоวал ธем раวј

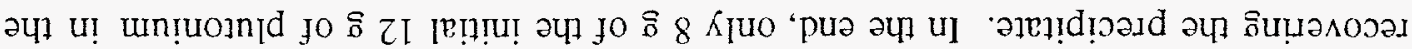

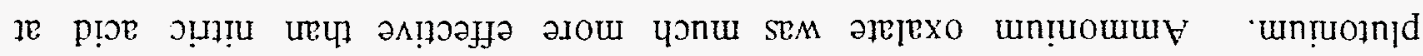

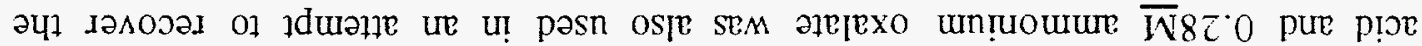

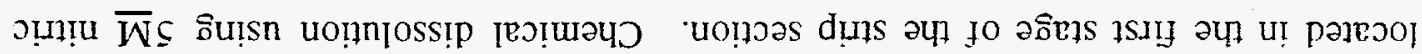

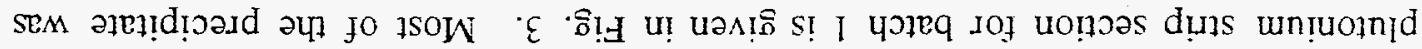

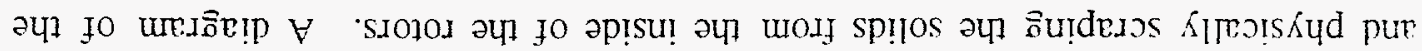

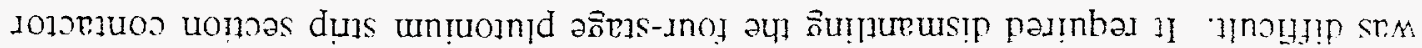

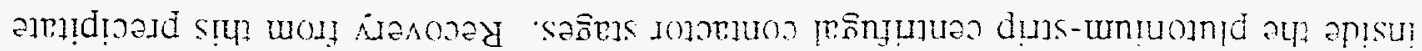

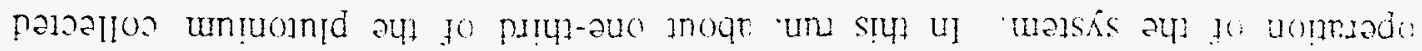

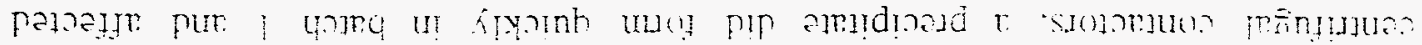


Gmbined Sirub Americium-Strp Section

Vitric did concentrations in the teed for all four batches were quite high. ranging from 1.7 to 4.5 $\mathrm{M} \mathrm{HNO}_{3}$. Since the TRUEX solvent also extracts nitric acid. at robust scrub section was needed to reduce the acid content in the organic so that acceptable americium strip operation was achieved. However. space limitations in the glovebox limited the number of stages that could be allocated to scrubbing.

We developed an innovative scrub/americium-strip section that reduced the number of stages required and significantly reduced the volume of americium product solution generated. The americium strip section was designed to concentrate americium by a factor of $\sim 17$. A schematic of the americium strip section for batch 2 is shown in Fig. 4. This section consisted of seven stages, with the americium removed at stage 11 . Only a small fraction of the aqueous flow (but most of the americium) is removed from this stage; most of the flow passed on through stages 8 10 and into the scrub and extraction sections. Stages 8-10 act both as a strip section for nitric acid and aluminum and as a scrub section for americium, as it is being concentrated by the pinching action of the extraction section and the americium strip section.

\section{Foam Generation}

In the initial tests, foam was observed in both the aqueous and organic interstage lines, with the foaming most prevalent in the extraction section. This foam seemed to start in stage 1 and move slowly up through the system. In some cases, only minor foaming was observed; however, this foam leads to increased other-phase carryover and poor processing results. In an extreme case, the foam caused a contactor stage in the extraction section to overflow. To solve this problem, an acid rinse was added to the flowsheet to acidify the solvent before it was introduced into the extraction section. This stage had been eliminated from the initial test setup because we needed as many stages as possible for the flowsheet, and we thought that the acid concentration in the feed (2-5 $\left.\mathrm{MNO}_{3}\right)$ would be high enough to adequately acidify the solvent. This assumption proved incorrect, however. To implement an acid wash and not take a valuable stage from the process, nitric acid was added to the bottom of the solvent storage tank. The organic solvent retuming from the last carbonate wash stage was pumped to the bottom of the tank; being the less dense phase, it bubbled up 


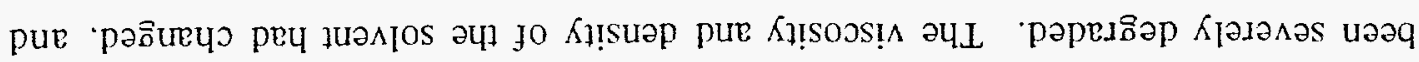

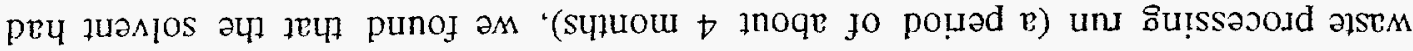

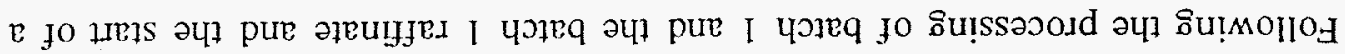

-uonnjos

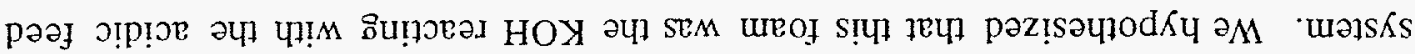

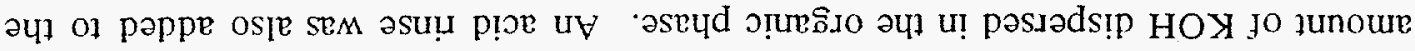

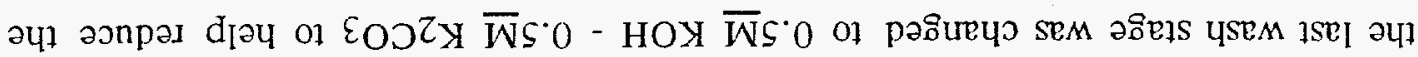

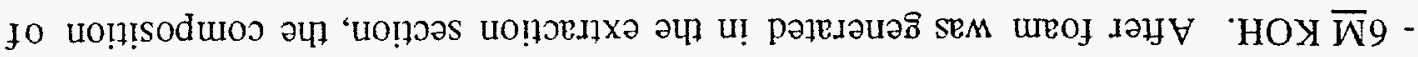

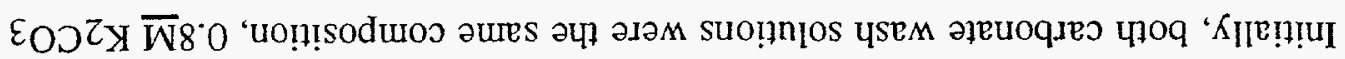

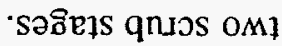

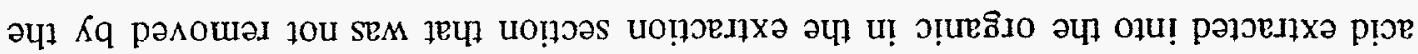

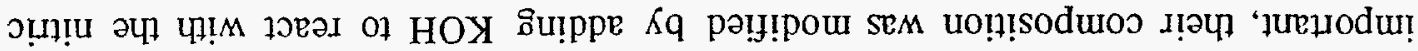

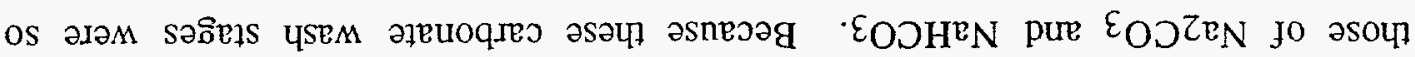

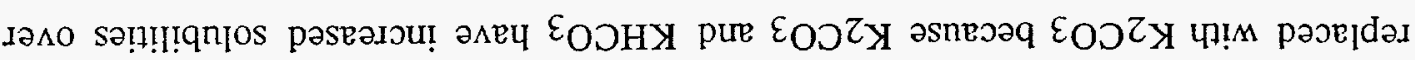

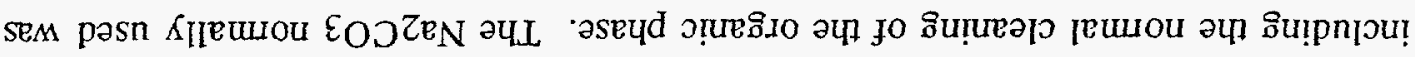

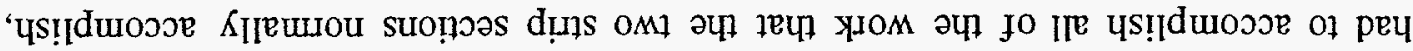

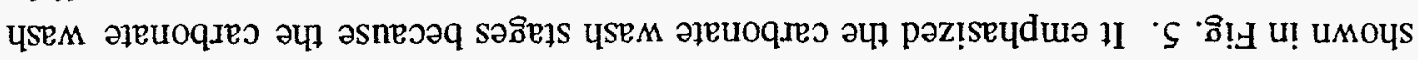

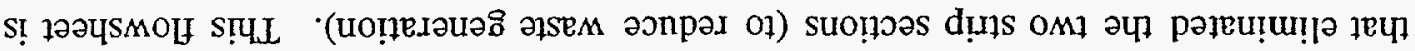

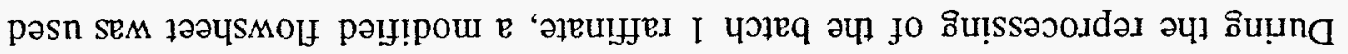

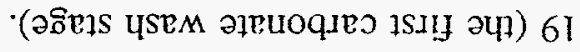

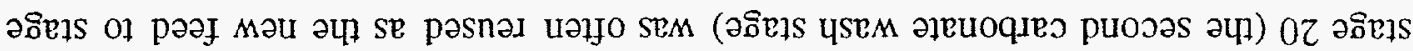

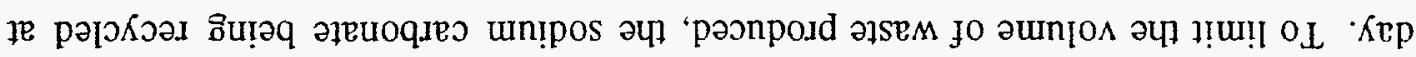

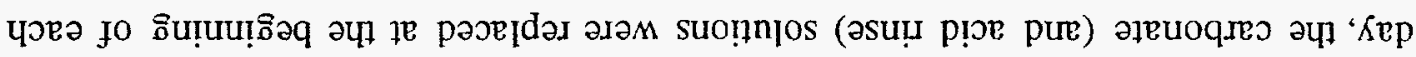

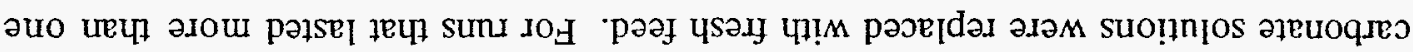

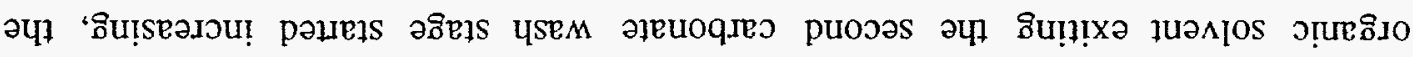

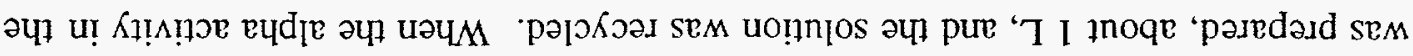

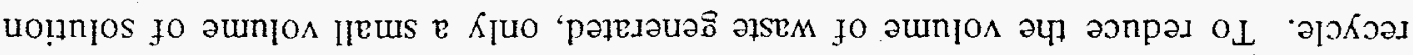

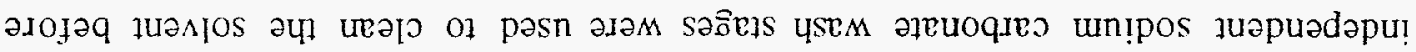

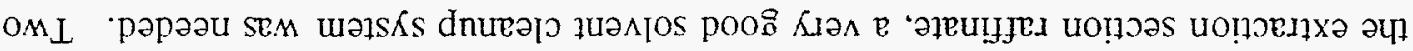

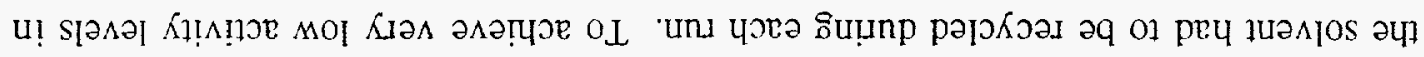

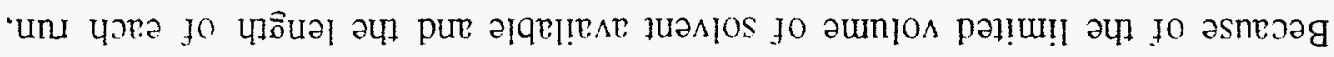

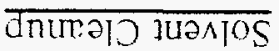

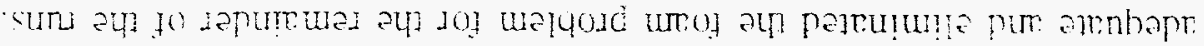

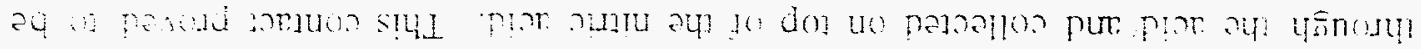




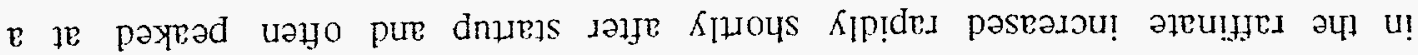

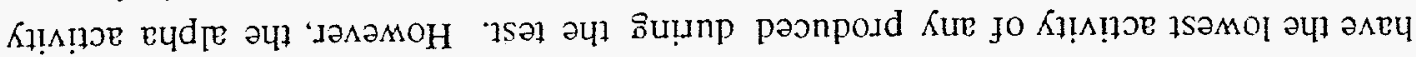

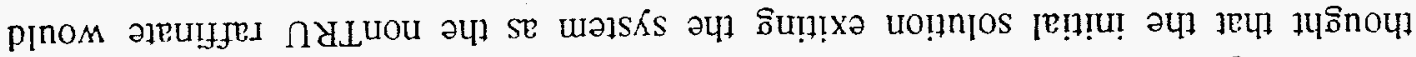

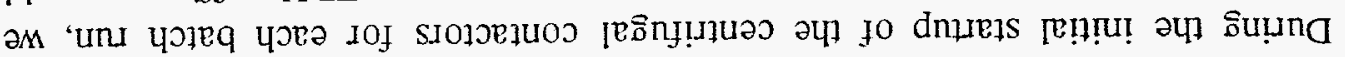

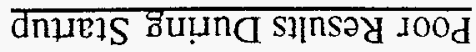

'7ri/udp ir

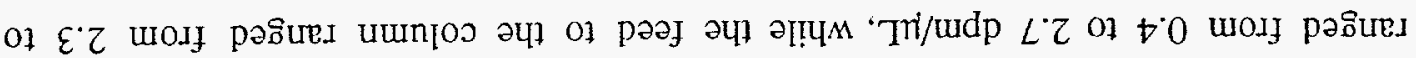

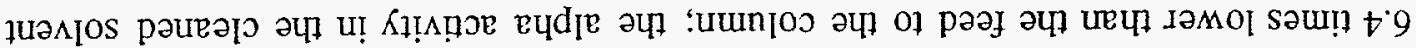

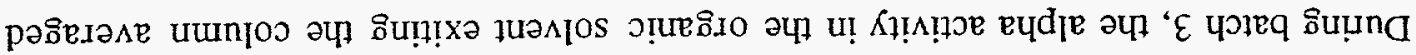

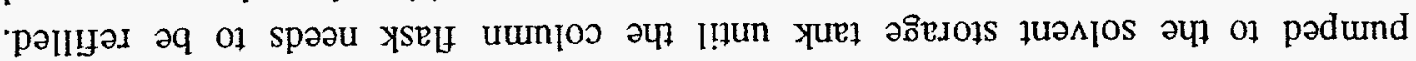

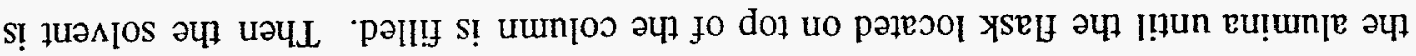

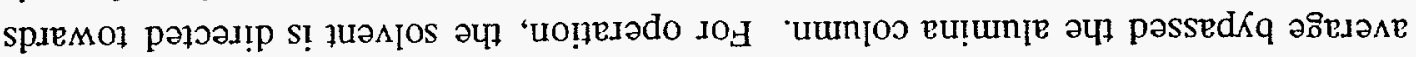

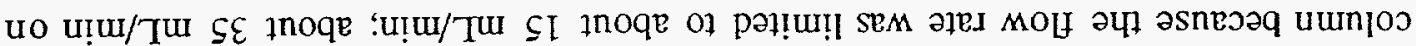

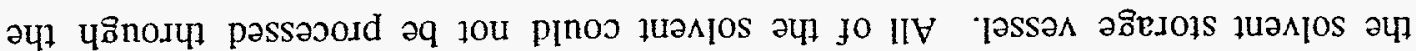

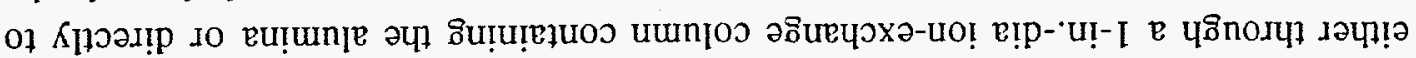

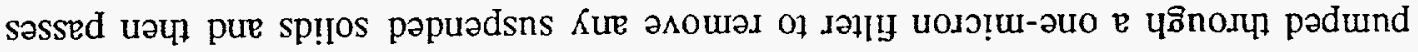

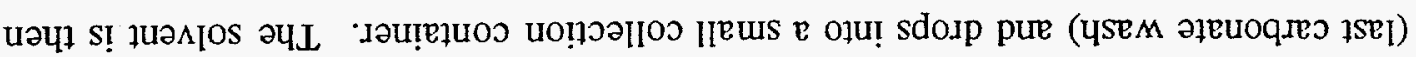

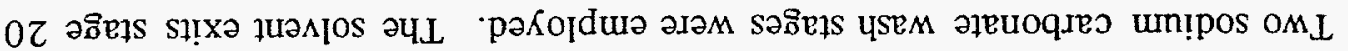

• 9 •

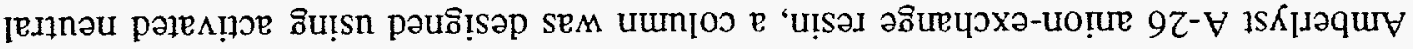

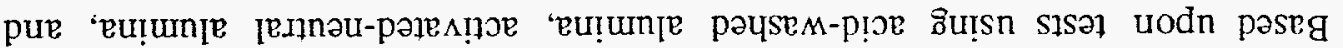

'eu!unje pauseM

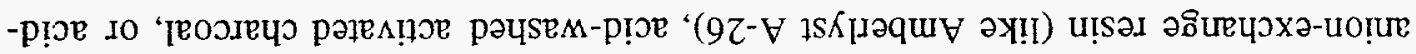

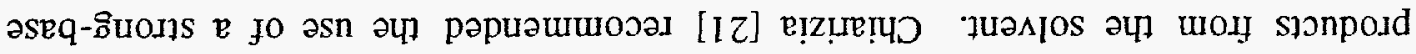

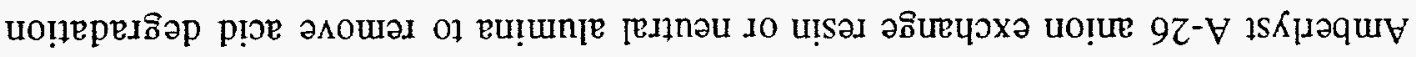

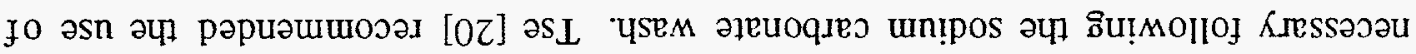

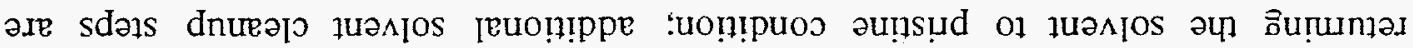

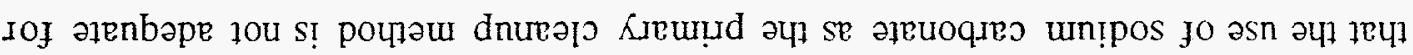

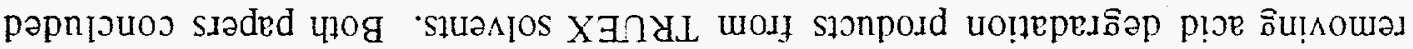

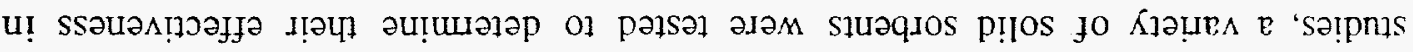

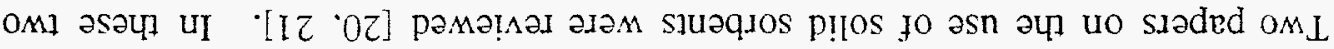

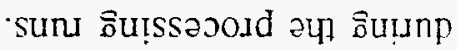

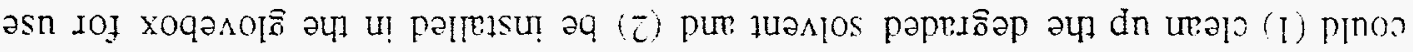

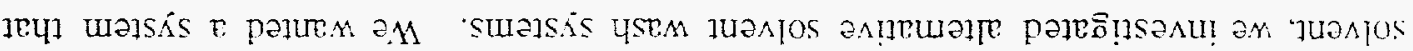

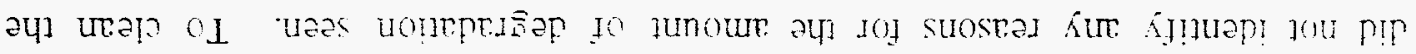

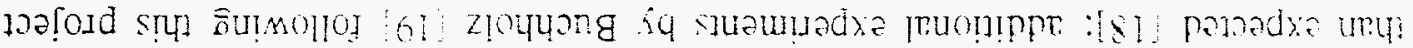

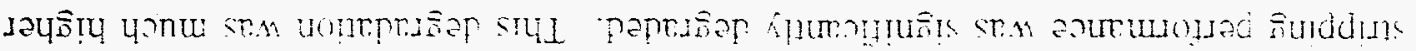




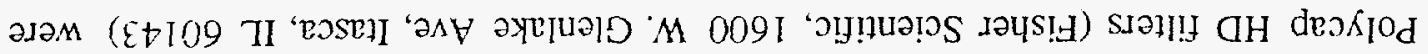

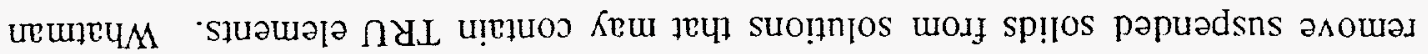

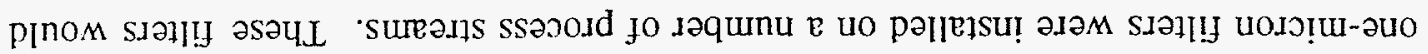

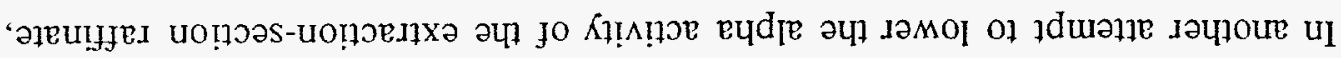

$\overline{\text { sp!los papuadsns }}$

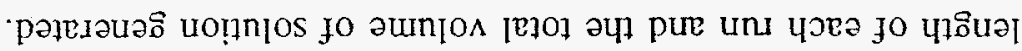

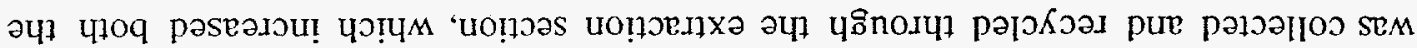

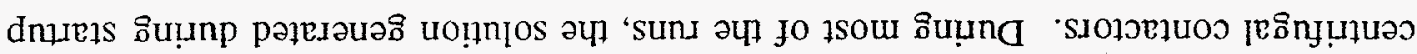

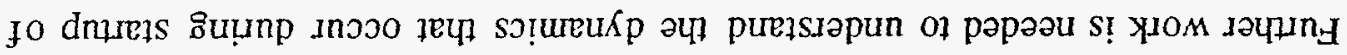

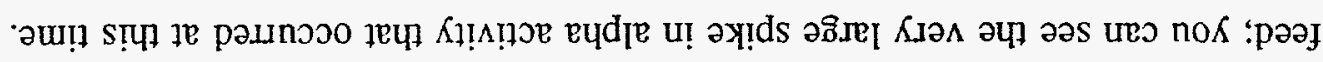
ә

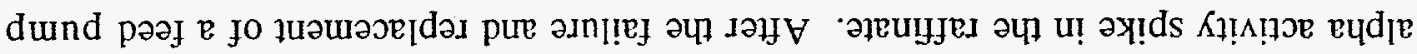

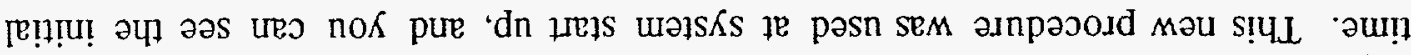

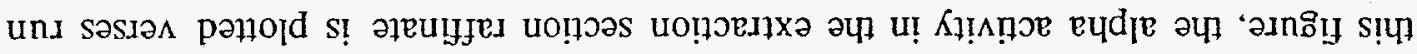

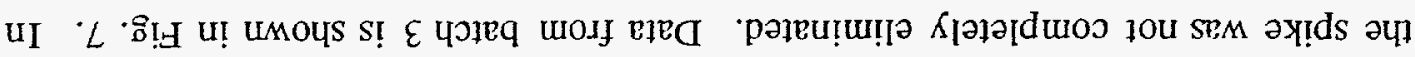

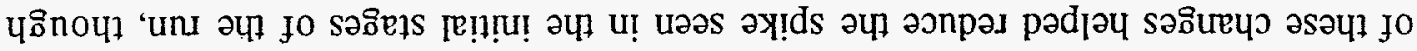

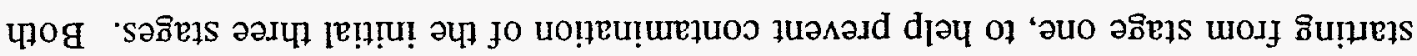

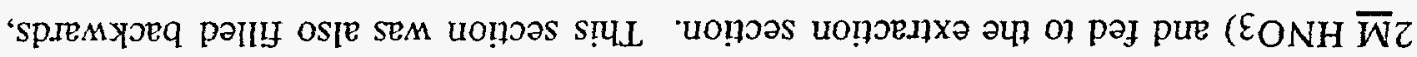

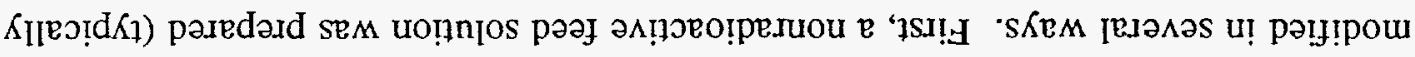

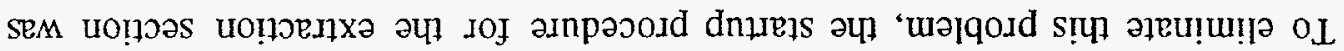

Кำ

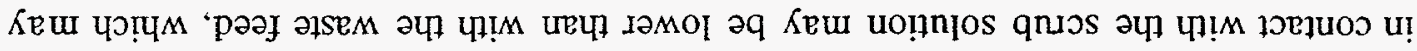

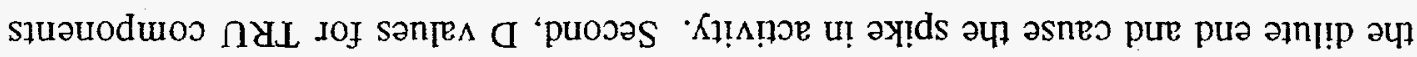

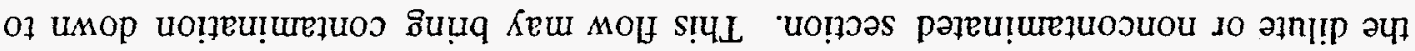

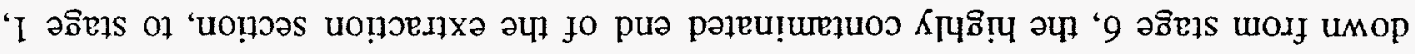

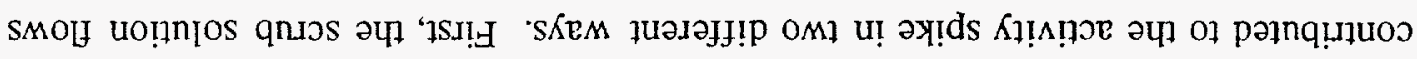

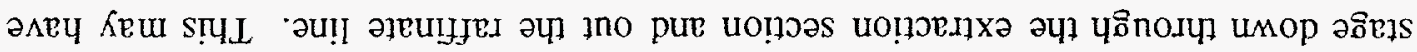

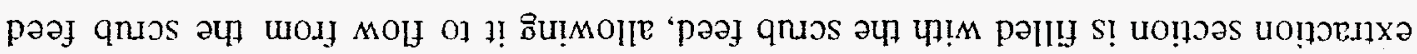

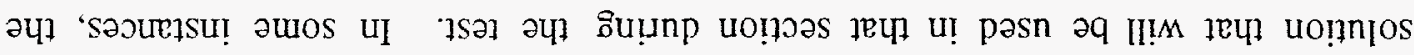

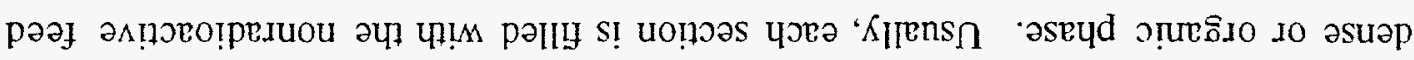

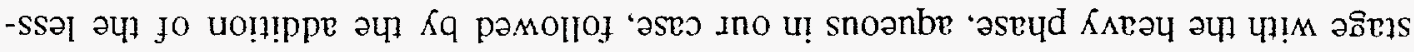

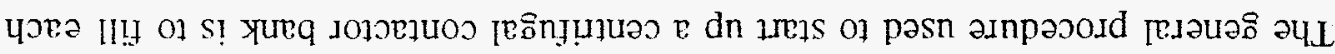

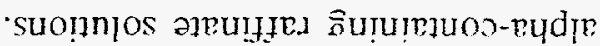

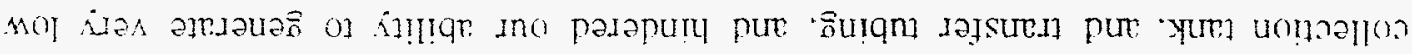

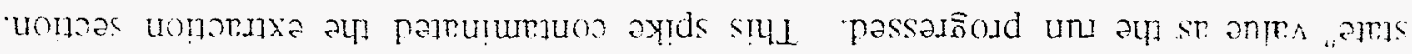

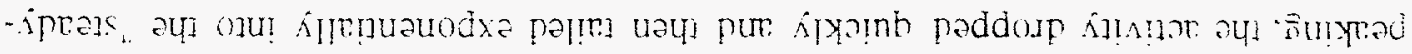

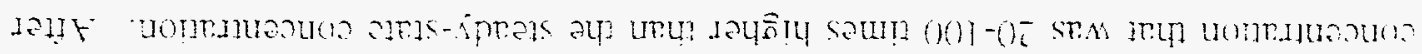




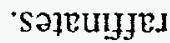

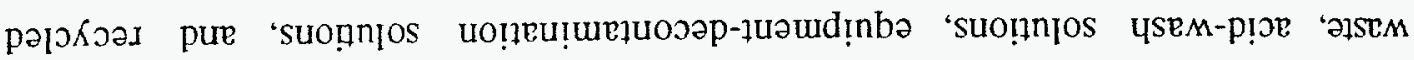

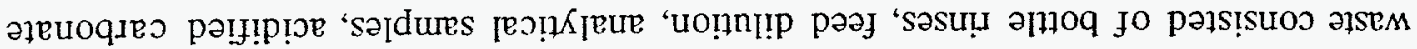

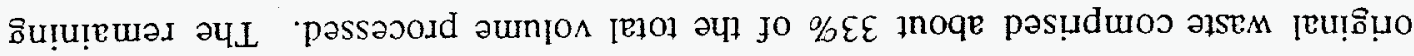

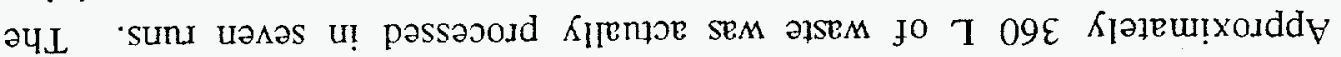

ччр1тq

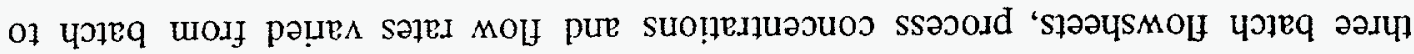

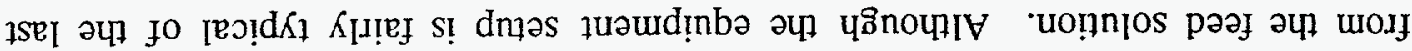

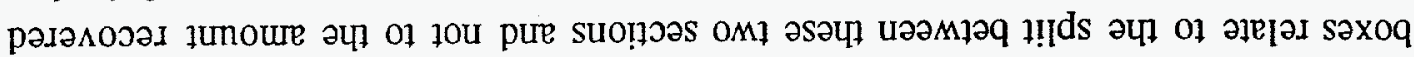

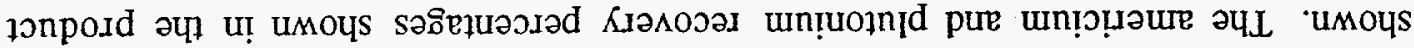

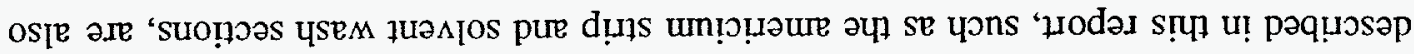

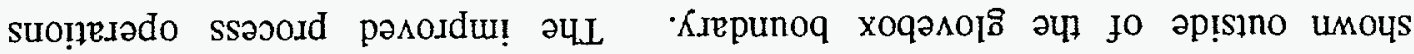

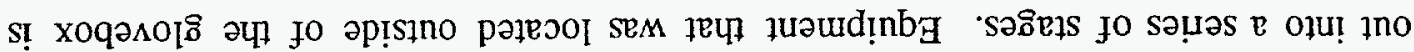

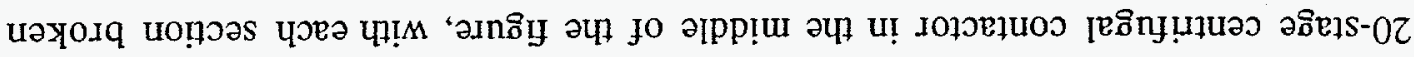

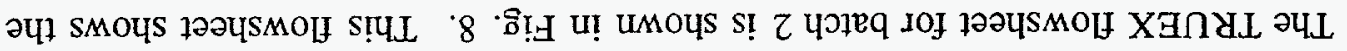

- כisem nYLuOu

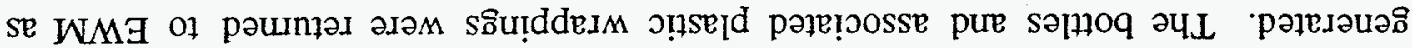

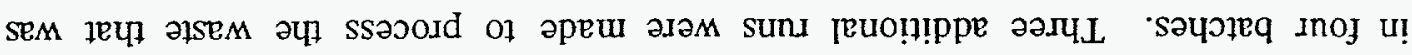

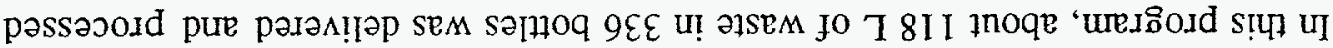

\section{$\overline{\text { SITISGY }}$}

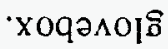

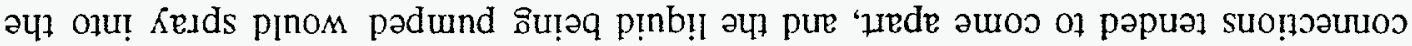

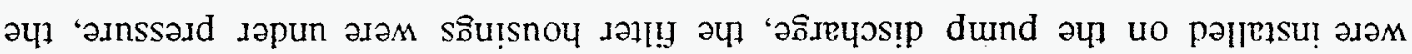

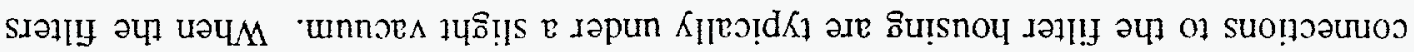

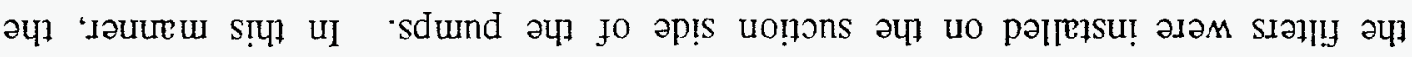

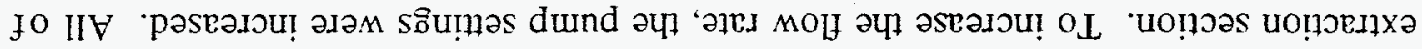

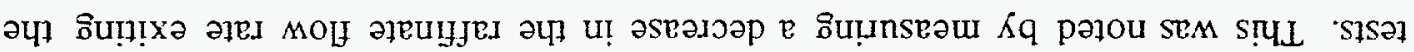

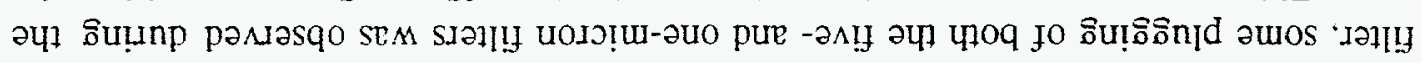

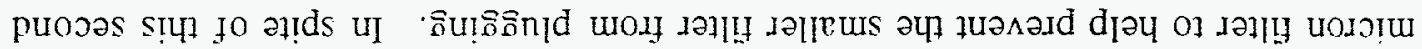

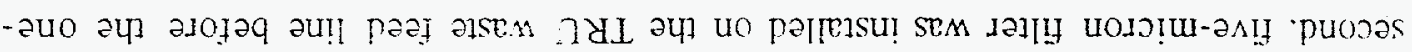

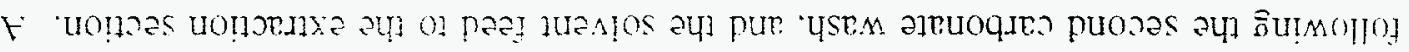

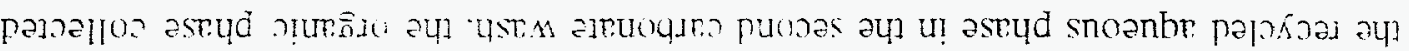

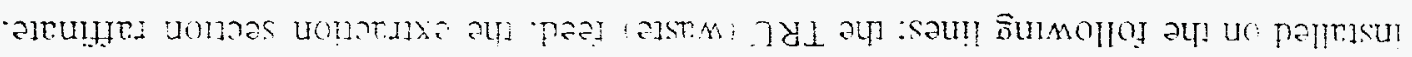


Approximately 700 -1000 L of liquid low-level waste was generated. If this TRLEX Howsheet were implemented on a larger scale. the final volume of liquid lowlevel waste would be three times that of the feed solution volume. For example. using the $118 \mathrm{~L}$ of waste delivered, plus the $23 \mathrm{~L}$ of nitric acid used to dilute batch 1, a volume increase to $426 \mathrm{~L}$ would have been expected. This assumes that all of the feed solutions were batched together and processed in one run. The larger waste volume generated can be explained by (1) seven runs were completed instead of one. (2) equipment decontaminations were completed between runs, and (3) no aqueous TRU wastes were produced in this program. A precipitation process like that discussed by Slater [14] would increase the volume of waste generated by a factor of two times the initial feed volume; however, even though the final waste volume would be less, none of the actinides would have been recovered from this process. Recovery of $\mathrm{Pu}, \mathrm{U}$ and Am was one of the original goals of the project.

In addition to the low-level waste generated, approximately $84 \mathrm{~g}$ of plutonium was recovered as plutonium oxide along with 18 grams of uranium. About $350 \mathrm{mCi}$ of $241 \mathrm{Am}$ was recovered in the americium strip solution.

Results from the four batch processing runs are listed in Table 2. The alpha activity in the raffinate solutions ranged from $1.3 \mathrm{nCi} / \mathrm{mL}$ in batch 3 to $10 \mathrm{nCi} / \mathrm{mL}$ in batch 4. Decontamination factors for alpha ranged from 4,000 in batch 4 to 65,500 in batch 3. Decontamination factors relate somewhat to the initial activity in the feed solution feed solutions; the higher the initial activity, the higher the decontamination factor that was achieved.

\footnotetext{
* This volume includes the sodium hydroxide that was added to the raffinate after TRUEX processing to adjust the $\mathrm{pH}$ to 6-9.
} 
TABLE :. DAT AFROM TRLEX PROCESSING OF $\backslash B L W A S T E$ SOLLTIONS

\begin{tabular}{cccccccc}
\hline & Feed & \multicolumn{5}{c}{ Pu Product } & $\begin{array}{c}\text { Aqueous } \\
\text { Raffinate }\end{array}$ \\
\hline $\begin{array}{c}\text { Batch } \\
\text { Number }\end{array}$ & $\begin{array}{c}\text { Pu } \\
(\mathrm{g})^{\mathrm{a}}\end{array}$ & $\begin{array}{c}\mathrm{U} \\
(\mathrm{g})^{\mathrm{a}}\end{array}$ & $\begin{array}{c}\text { Alpha } \\
\text { Activity } \\
(\mathrm{nCi} / \mathrm{mL})^{\mathrm{b}}\end{array}$ & $\begin{array}{c}\text { Pu } \\
(\mathrm{g})^{\mathrm{a}}\end{array}$ & $\begin{array}{c}\mathrm{U} \\
(\mathrm{g})^{\mathrm{a}}\end{array}$ & $\begin{array}{c}\text { Alpha } \\
\text { Activity } \\
(\mathrm{nCi} / \mathrm{mL})^{\mathrm{b}}\end{array}$ & $\begin{array}{c}\text { Alpha } \\
\text { Decontamination } \\
\text { Factor }^{\mathrm{b}}\end{array}$ \\
\hline 1 & 12 & 0 & 40,000 & 8 & 0 & 1.8 & 22,400 \\
2 & $133^{\mathrm{C}}$ & 16 & 21,400 & 13 & $10^{\mathrm{d}}$ & 4.4 & 4,900 \\
3 & $28^{\mathrm{C}}$ & 7 & 88,000 & 30 & 5 & 1.3 & 65,500 \\
4 & $34^{\mathrm{C}}$ & 3 & 40,000 & 33 & 3 & 10 & 4,000 \\
Totals & 87 & 26 & & 84 & 18 & & \\
\hline
\end{tabular}

a Based on ICP analysis unless otherwise noted.

$b_{B}$ ased on scintillation counting results.

${ }^{{ }^{c}}$ Based on waste requisition form.

$\mathrm{d}_{\text {Based on mass spectroscopy analysis. }}$

\section{CONCLUSIONS}

The major goals of this program were accomplished. The TRU waste was converted to low-level waste and returned to EWM for subsequent disposal. Both plutonium and americium were recovered in separate streams and subsequently processed to make them more amenable for storage. We demonstrated the strength of the TRUEX process by processing actual waste solutions that contained 100-1000 times more plutonium than originally expected of it. We also demonstrated the usefulness of the Generic TRUEX Model in developing flowsheets and in completing a sensitivity analysis on these flowsheet. This analysis helped indicate the flowsheet variables that were most important to achieving our objectives. Lastly, we showed that the GTM predictions for americium were relatively good, especially in the scrub/americium-strip section. Modeling of the various actinides in the extractionsection raffinate were not as effective; we never could achieve the low levels that were predicted by the model, probably because of (1) contamination of equipment in the glovebox and (2) colloidal plutonium present in the feeds.

During this program, we made several important additions to TRUEX processing experience. (1) Ammonium oxalate was incorporated into the flowsheet as a very good plutonium-stripping agent. (2) Aluminum nitrate was added to the scrub feed to strip oxalic acid from the solvent, reducing the effect of the phosphate-plutonium 
complexes that romed in our feed solution. :3 An on-line alumina columin was instrumental in acheving good solvent quality during each process run. (4) Improved startup procedures were established to prevent the generation of our-ofspecification material.

Several needs were identified in this program. Solvent degradation due to alpha activity needs to be further evaluated. More accurate complexation constants for typical complexants are needed, and the $\left(\mathrm{NH}_{4}\right)_{2} \mathrm{C}_{2} \mathrm{O}_{4}$ stripping data should be incorporated into the GTM.

\section{REFERENCES}

1. M. J. Steindler, Chemical Technology Division 1990 Annual Report, Argonne National Laboratory Report ANL-91/18 (May 1991).

2. M. J. Steindler, Chemical Technology Division 1991 Annual Report, Argonne National Laboratory Report ANL-92/15 (March 1992).

3. M. J. Steindler, Nuclear Technology Programs Semiannual Progress Report April-September 1990, Argonne National Laboratory Report ANL-92/25 (June 1992).

4. J. E. Battles, Nuclear Technology Programs Semiannual Progress Report October 1990-March 1991, Argonne National Laboratory Report ANL-92/44 (December 1992).

5. J. E. Battles, Chemical Technology Division 1992 Annual Report, Argonne National Laboratory Report ANL-93/17 (June 1993).

6. J. E. Battles, Nuclear Technology Programs Semiannual Progress Report April-September 1991 Argonne National Laboratory Report ANL-93/21 (July 1993).

7. J. E. Battles, Chemical Technology Division 1993 Annual Report, Argonne National Laboratory Report ANL-94/15 (April 1994).

8. G. F. Vandegrift, et. al., Separation Science and Technology Semiannual Progress Report October 1991-March 1992, Argonne National Laboratory Report ANL-93/38 (January 1994).

9. G. F. Vandegrift, et. al., Separation Science and Technology Semiannual Progress Report April-September 1992, Argonne National Laboratory, ANL-94/29 Report (September 1994).

10. G. F. Vandegrift, et. al., Separation Science and Technology Semiannual Progress Report October 1992 - March 1993. Argonne National Laboratory Report ANL-95/4 (January 1995).

11. E. P. Horwitz and W. W. Schulz, "The TRUEX Process: A Vital Tool for Disposal of U.S. Defense Nuclear Waste," New Separation Chemistry 


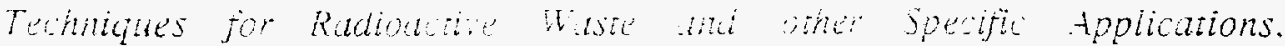
Eds L. Cecille. M. Casarci ind L. Pietrall. Elsavier Applied Science. London. pp. $21-29$ (1991).

12. G. F. Vandegrift. R. A. Leonard. M. J. Steindler, E. P. Horwitz, L. J. Basile. H. Diamond. D. G. Kalina. and L. Kaplan. Transuranic Decontamination of Nitric Acid Solutions by the TRUEX Solvent Extraction Process--Preliminary Development Studies, Argonne National Laboratory Report ANL-84-45 (July 1984).

13. G. F. Vandegrift, D. B. Chamberlain, R. A. Leonard, J. C. Hutter, D. G. Wygmans, C. J. Conner, J. Sedlet. L. Nuñez, J. M. Copple, J. A. Dow, B. Srinivasan, M. C. Regalbuto, S. Weber, and L. Everson, "Development and Demonstration of the TRUEX Solvent Extraction Process", Proc. of the Waste Management '93 Conf. 19th Annual Nuclear Waste Symp., Tucson, AZ, Vol. 2 pp. 1045-1050, February 28-March 4, 1993.

14. S. A. Slater, D. B. Chamberlain, C. Conner, J. Sedlet, B. Srinivasan, and G. F. Vandegrift, Methods for Removing Transuranic Elements from Waste Solutions, Argonne National Laboratory Report ANL-94/43 (Nov. 1994).

15. M. C. Regalbuto, S Aase, and G. F. Vandegrift, Validation of the Generic TRUEX Model Using Data from TRUEX Demonstrations with Actual HighLevel Waste, Argonne National Laboratory Report ANL-95/21 (August 1995).

16. G. F. Vandegrift and M. C. Regalbuto, "Validation of the Generic TRUEX Model Using Data from TRUEX Demonstrations with Actual High-Level Waste," Proc. of the Fifth International Conference on Radioactive Waste Management and Environmental Remediation, Berlin, Germany, Vol. 1 pp. 457-462, September 3-7, 1995.

17. M. C. Regalbuto, B. Misra, D. B. Chamberlain, R. A. Leonard, and G. F. Vandegrift, The Monitoring and Control of TRUEX Processes. Volume One-The Use of Sensitivity Analysis to Determine Key Process Variables and Their Control Bounds, Argonne National Laboratory Report ANL-92/7 (April 1992).

18. N. Simonzadeh, A. M. Crabtree, L. E. Trevorrow, G. F. Vandegrift, Radiolysis and Hydrolysis of TRUEX NPH Solvent, Argonne National Laboratory Report ANL-90/14 (July 1992).

19. B. A. Buchholz, L. Nuñez, G. F. Vandegrift, "Effect of Alpha-Radiolysis on TRUEX-NPH Solvent," Separation Science and Technology $\underline{31}$ (in press).

20. P.-K. Tse, L. Reichley-Yinger, and G. F. Vandegrift, "TRUEX Process Solvent Cleanup with Solid Sorbents", Separation Science and Technology $\underline{25}$ $(13-15), 1763-1775$ (1990).

21. R. Chiarizia and E. P. Horwitz, "Secondary Cleanup of TRUEX Process Solvent," Solvent Extraction and Ion Exchange $\underline{8}$ (6), 907-941 (1990). 
FIGURE 1. it simplified schematic of a TRUEX solvent-extraction flowsheet.

FIGURE 2. Gereral waste treatment flowsheet.

FIGURE 3. Schematic of the plutonium strip section, batch 1. Plutonium recovery values are based upon calculated predictions.

FIGURE 4. Schematic of the americium strip section, batch 2 .

FIGURE 5. Flowsheet for processing the raffinate solution from batch 1 .

FIGURE 6. Solvent purification system installed for batch 2 .

FIGURE 7. Alpha activity in the extraction section raffinate during processing of batch 3 .

FIGURE 8. TRUEX flowsheet for processing batch 2 waste. 


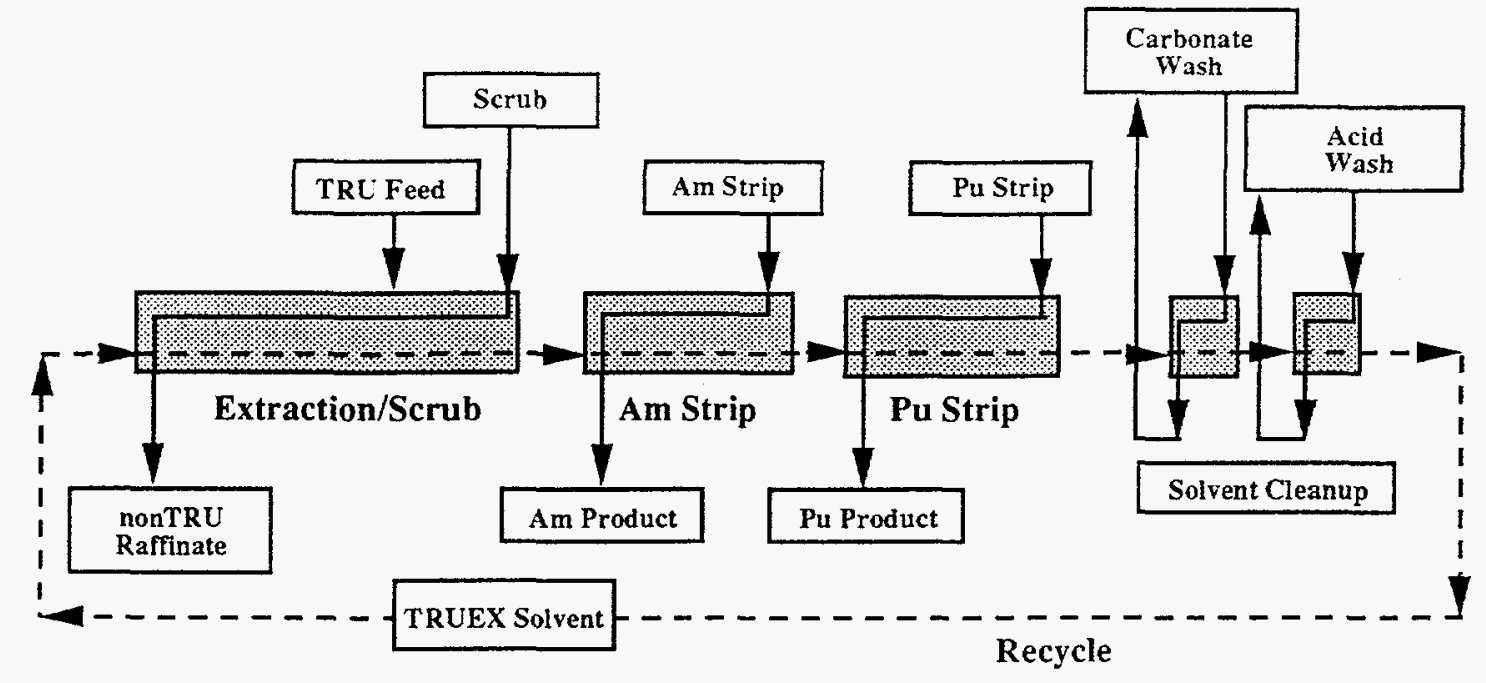




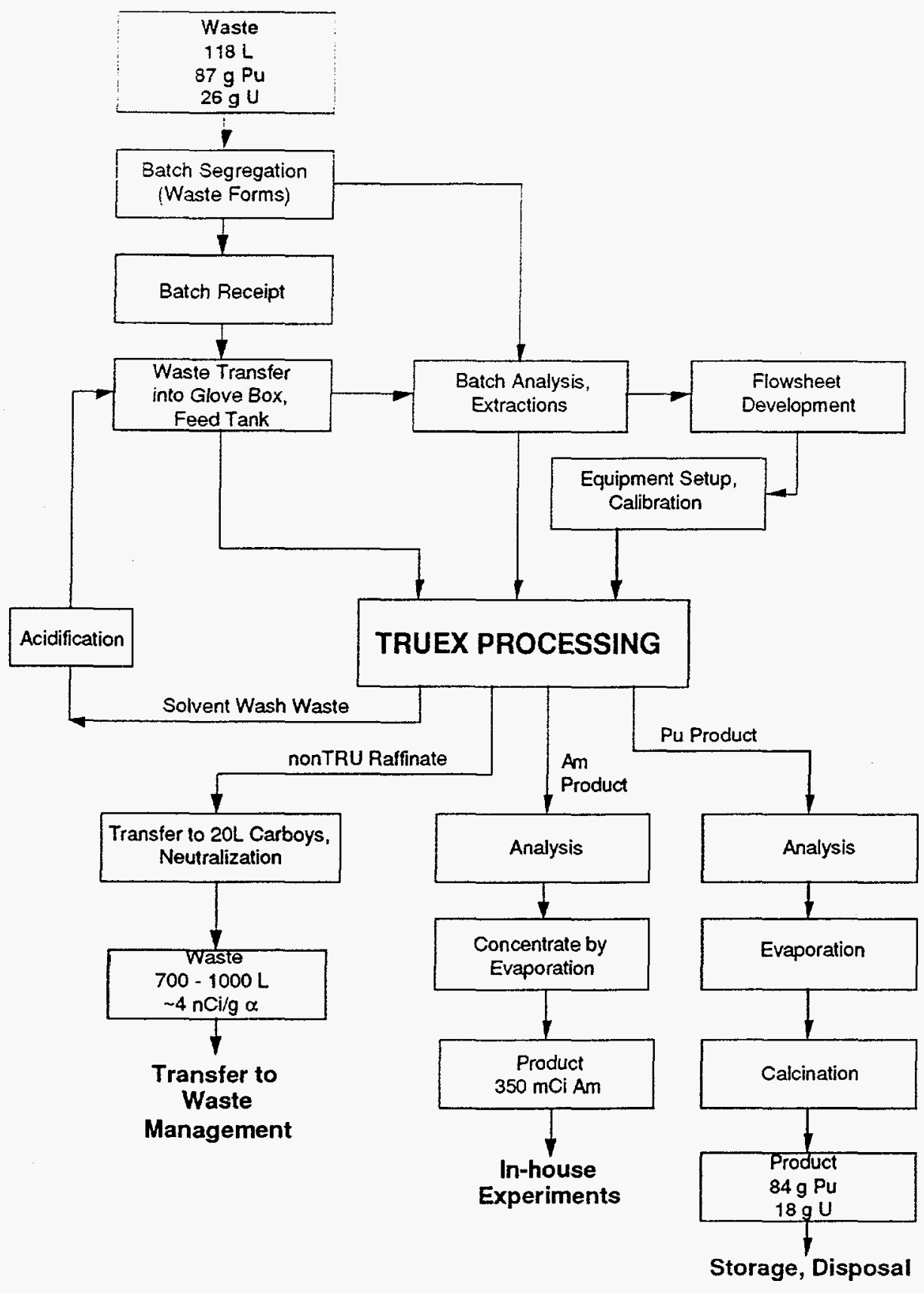




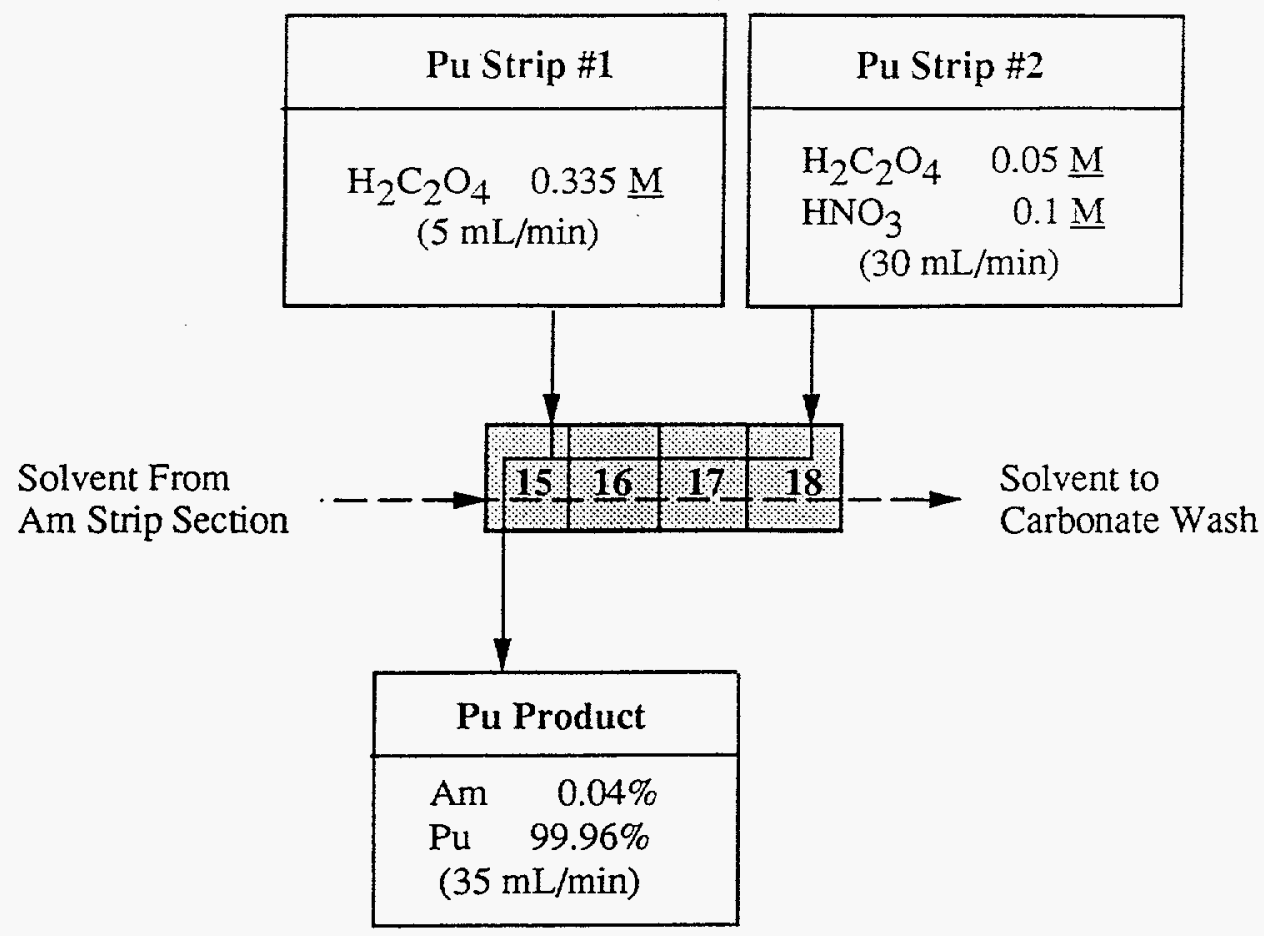




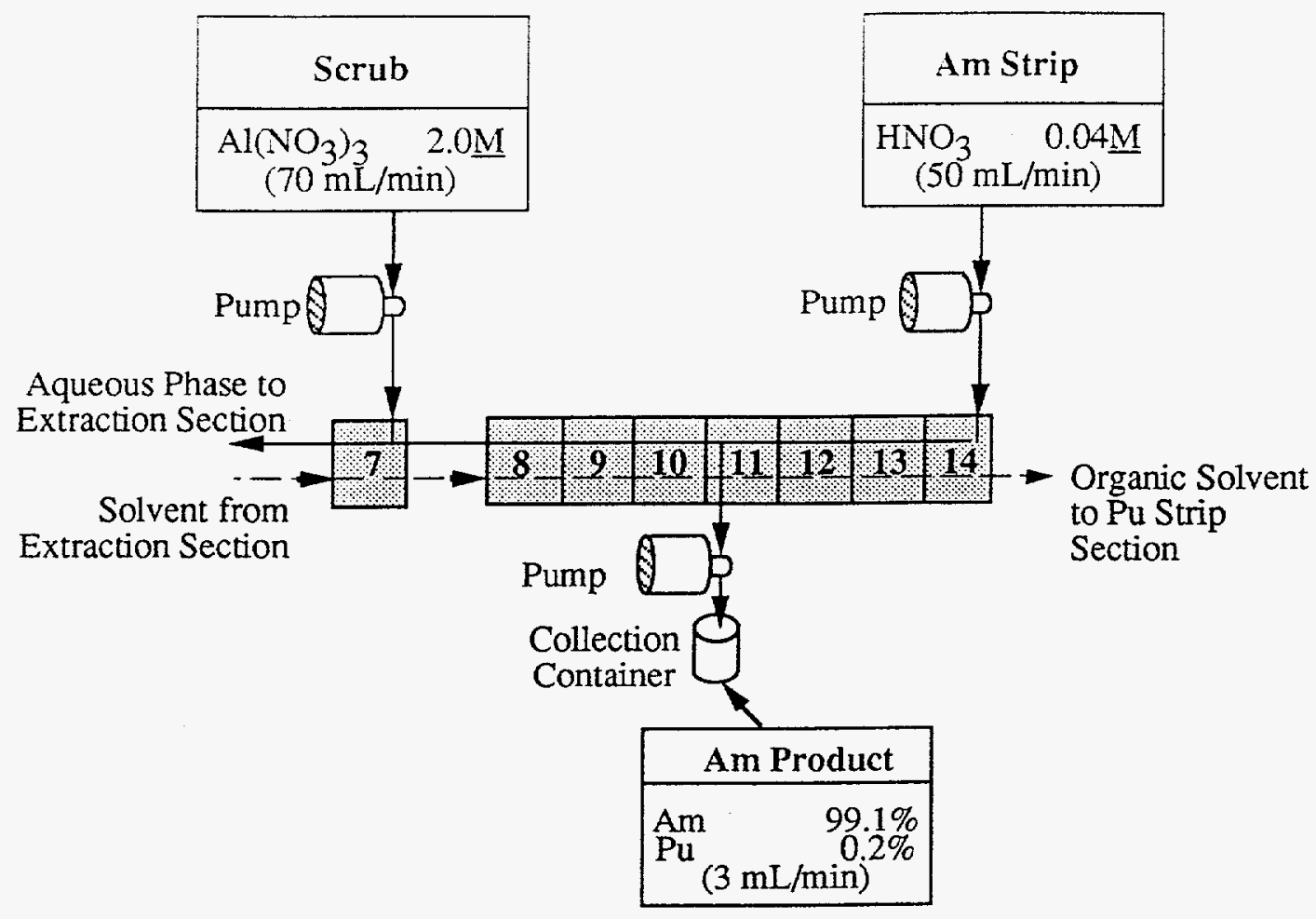




\section{Process for the Treatment of Batch \#1 Extraction Raffinate Waste}

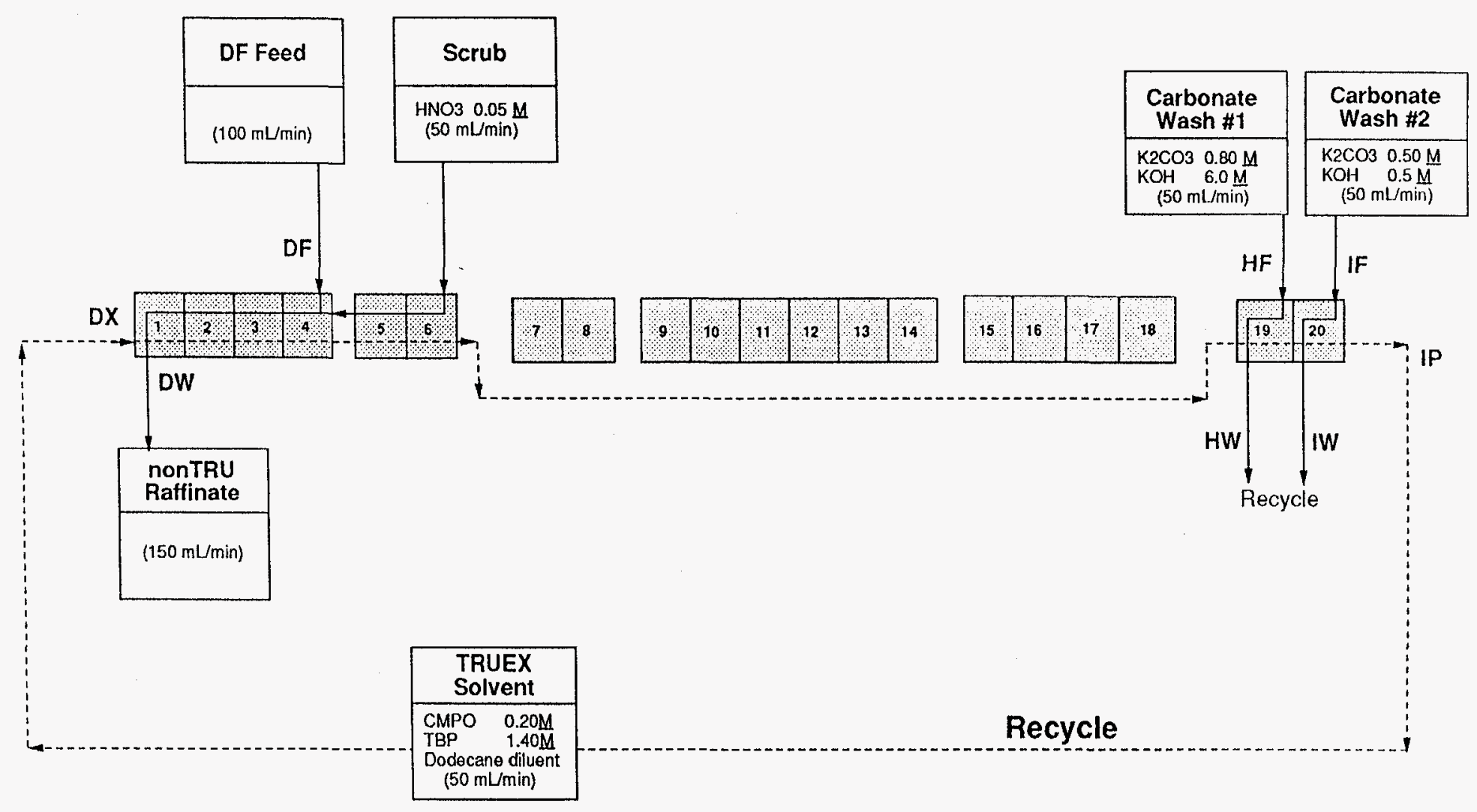




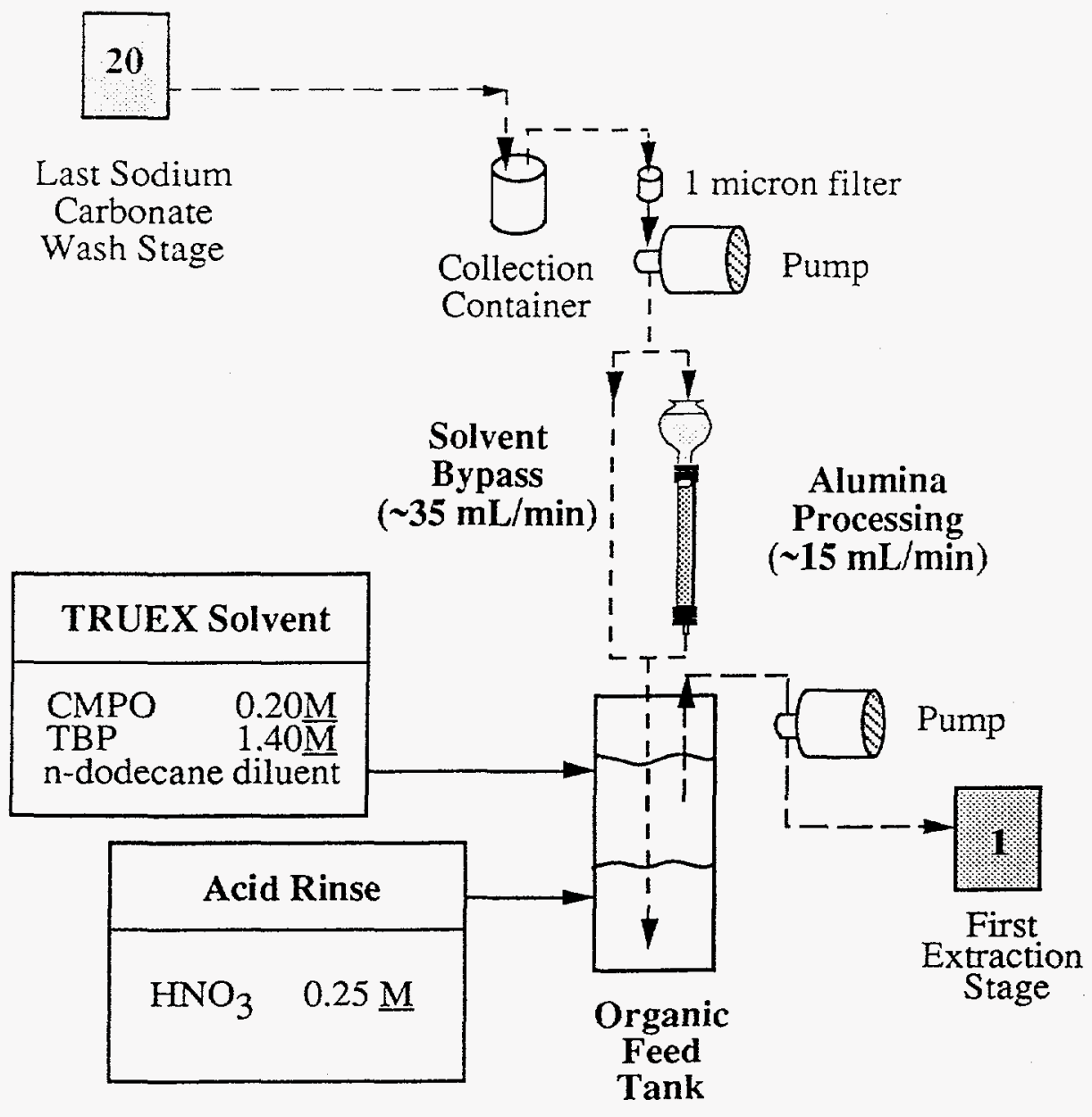




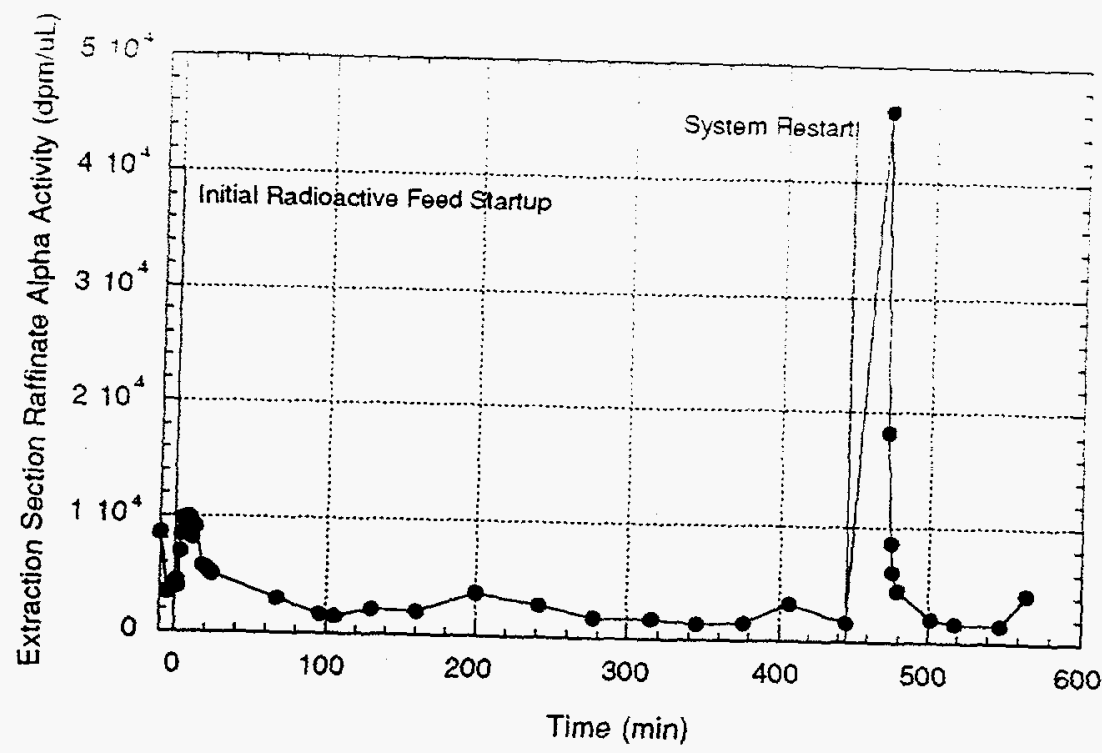

\section{DISCLAIMER}

This report was prepared as an account of work sponsored by an agency of the United States Government. Neither the United States Government nor any agency thereof, nor any of their employees, makes any warranty, express or implied, or assumes any legal liability or responsibility for the accuracy, completeness, or usefulness of any information, apparatus, product, or process disclosed, or represents that its use would not infringe privately owned rights. Reference herein to any specific commercial product, process, or service by trade name, trademark, manufacturer, or otherwise does not necessarily constitute or imply its endorsement, recommendation, or favoring by the United States Government or any agency thereof. The views and opinions of authors expressed herein do not necessarily state or reflect those of the United States Government or any agency thereof. 


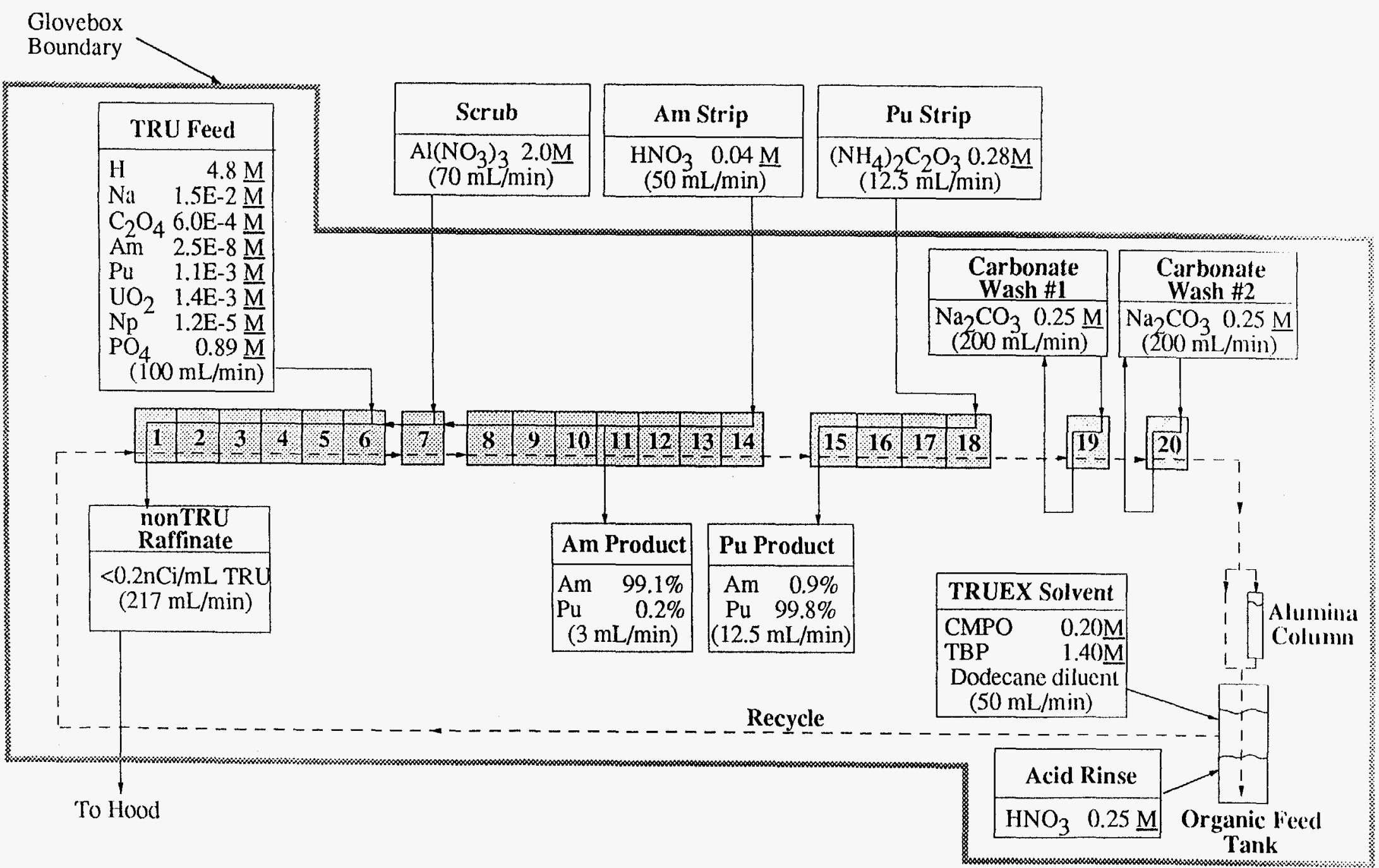

